\title{
[ECO] TURISMO UNA ALTERNATIVA DE DESARROLLO [SOSTENIBLE] PARA EL [SUB] DESARROLLO. UN ESTUDIO COMPARATIVO ENTRE LOS POBLADOS DE SAN CLEMENTE Y EL RECUERDO.
}

Paola García Noboa'

\section{RESUMEN}

EN EL ÚLTIMO TERCIO DEL SIGLO XX EL TURISMO HA SIDO UNA DE LAS INDUSTRIAS, DENTRO DEL ÁREA DE SERVICIOS, QUE MANIFIESTA UNO DE LOS CRECIMIENTOS ECONÓMICOS MÁS ACELERADOS EN EL MUNDO. SUS INGRESOS DE EXPORTACIÓN A NIVEL MUNDIAL OCUPAN LA CUARTA POSICIÓN DESPUÉS DE LOS COMBUSTIBLES, LOS PRODUCTOS QUíMICOS Y LOS

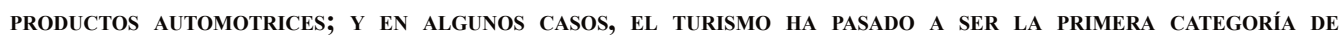
EXPORTACIÓN EN LOS PAÍSES SUBDESARROLLADOS (OMT, 2008).

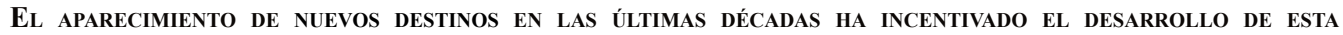
INDUSTRIA, QUE ENTRE 1995 Y 2007 EXPERIMENTÓ UN CRECIMIENTO PROMEDIO ANUAL DEL 4\% (IDEM). EN GRAN MEDIDA ESTOS NUEVOS DESTINOS SON PARTE DE PROPUESTAS ECOLÓGICAS INSCRITAS DENTRO DEL DISCURSO DEL DESARROLLO SOSTENIBLE, CONCEBIDAS COMO PROYECTOS ALTERNATIVOS DE (ECO) TURISMO A PEQUEÑa ESCALA EN REGIONES SUBDESARROLLADAS CON GRAN BIODIVERSIDAD, CUYO PROPÓSITO ES PROMOVER EL DESARROLLO LOCAL Y LA CONSERVACIÓN DE LA NATURALEZA.

TOMANDO EN CUENTA ESTE CONTEXTO, NOS INTERESA ANALIZAR DESDE UNA VISIÓN ANTROPOLÓGICA, LAS POSIBILIDADES DE ÉXITO DEL (ECO) TURISMO EN DOS LOCALIDADES DEL ECUADOR, PARA LO CUAL EL PRESENTE ARTículO SE HA DIVIDIDO EN DOS PARTES: LA PRIMERA, ES UN BREVE ESBOZO HISTÓRICO DEL PARADIGMA DEL DESARROLLO Y SU VÍNCULO CON LA

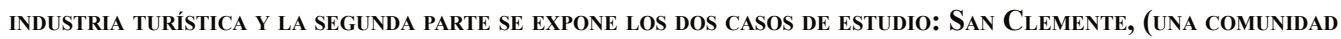
indíGena de Kichwa- hablantes, localizada en la provincia de Imbabura) y El Recuerdo, (Un Recinto MONTUBIO UBICAdo EN LA PROVINCIA DE Los Ríos), Y SU RELACIÓN HISTÓRICA CON EL DISCURSO DEL DESARROLLO A TRAVÉS de PROyectos PUNTUALes COMO PARTE DE LA LÓGICA PROYECTIVISTA DE INTERVENCIÓN, YA SEA POR PARTE DEL ESTADO O DE ORGANISMOS NO GUBERNAMENTALES.

Palabras Clave: desarrollo sostenible; (eco) turismo; desarrollo local, naturaleza, Conservación.

\section{Abstract}

IN THE LAST THIRD OF THE XX CENTURY, TOURISM HAS BEEN ONE OF THE MOST ACCELERATED ECONOMIC GROWTH INDUSTRIES WITHIN THE SERVICE AREA, IN THE WORLD. IT'S EXPORT GLOBAL INCOME IS RANKED FOURTH AFTER FUELS, CHEMICALS AND AUTOMOTIVE PRODUCTS, AND IN SOME CASES, THE TOURISM HAS BECOME THE FIRST EXPORTATION CATEGORY OF DEVELOPING COUNTRIES (WTO, 2008).

THE EMERGENCE OF NEW DESTINATIONS IN RECENT DECADES HAS ENCOURAGED THE DEVELOPMENT OF THIS INDUSTRY THUS BETWEEN 1995 AND 2007 THE ANNUAL AVERAGE GREW TO 4\% (IDEM). LARGELY THESE NEW DESTINATIONS ARE

1 Licenciada en Antropología, Escuela de Antropología PUCE. 
PART OF ECOLOGICAL PROPOSALS REGISTERED IN THE SUSTAINABLE DEVELOPMENT DISCOURSE, DESIGNED AS ALTERNATIVE (ECO) TOURISTIC PROJECTS AT SMALL SCALE IN UNDERDEVELOPED AREAS WITH GREAT BIODIVERSITY, WHOSE PURPOSE IS TO PROMOTE LOCAL DEVELOPMENT AND NATURE CONSERVATION.

CONSIDERING THIS CONTEXT, IT IS TO ANALYZE FROM AN ANTHROPOLOGICAL VIEW, THE SUCCES POSIBILITIES OF (ECO) TOURISM IN TWO SETLEMENTS OF ECUADOR, FOR WHAT THIS ARTICLE HAS BEEN DIVIDED INTO TWO PARTS: THE FIRST ONE IS A SHORT HISTORICAL OUTLINE OF THE PARADIGM OF DEVELOPMENT AND IT'S RELATIONSHIP TO THE TOURISM INDUSTRY

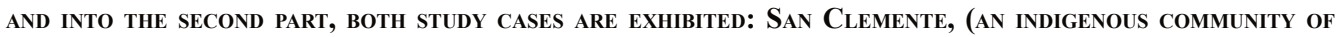
KICHWA SPEAKERS, LOCATED IN THE PROVINCE OF IMbabuRa) AND El RECUERdo (a MONTUbio ENClOSURE LOCATED IN THE PROVINCE OF LOS RÍOS) AND ITS RELATIONSHIP WITH THE HISTORICAL DISCOURSE OF DEVELOPMENT PROJECTS THROUGH SOME POINT OF THE PROJECT LOGIC INTERVENTION WHETHER BY THE STATE OR NON-GOVERNMENTAL ORGANIZATIONS.

KEY WORDS: SUSTAINABLE DEVELOPMENT; (ECO) TOURISTIC; LOCAL DEVELOPMENT; NATURE; CONSERVATION.

\section{Introducción}

$\mathrm{C}$ on el triunfo de la razón como el indicador hegemónico de progreso humano, -legitimado por el pensamiento ilustrado-, la Europa occidental del siglo XVIII pasó a ser el referente de civilización, a partir del cual se mediría el resto de pueblos en el planeta. En comparación a ésta -y pese a que el intelecto se reconocía como parte inherente a la condición humana- era claro para los pensadores de aquella época que no todas las sociedades habían conseguido utilizarlo adecuadamente, y muestra de ello era justamente la existencia de los denominados pueblos primitivos; mientras que, acontecimientos como la primera revolución industrial en la Inglaterra de 1780, eran prueba fehaciente de que el uso "correcto" de la razón permitía mejorar las condiciones de vida de las personas (Cfr. Díaz Polanco, 1989).

Este principio subyacente de superioridad, no solo que ordenó a las sociedades en términos de evolución racional, sino que además justificó la consolidación del Imperialismo a comienzos del siglo XIX, pues las grandes potencias de la época, expandieron su ocupación colonial hacia otras regiones del planeta como parte de su "misión civilizatoria". Bajo una ideología del progreso, los imperios de Inglaterra, Francia y España lideraron la tarea de ayudar a los pueblos primitivos a avanzar más rápidamente hacia el progreso (Ibíd.).

Siendo el mayor mérito de la razón, el control y la transformación de la naturaleza para el bienestar humano, el usufructo de los recursos naturales de las regiones colonizadas, no solo sería el pago para los colonizadores por su "labor misionera", sino también, la muestra empírica de desarrollo técnico humano, que en última instancia terminaría de encarnar el pensamiento positivista (fase científica) del siglo XX, es decir, la expresión más avanzada del desarrollo mental de la humanidad que decretaría la "...universalidad e inevitabilidad del progreso humano" (Ibíd: 34).

Después de la II Guerra Mundial, con la creación de Naciones Unidas en 1945, y la declaratoria universal de los Derechos Humanos (Rist, 2002) la ideología del progreso encontró su símil en el nuevo paradigma del desarrollo. Frente a la caducidad del orden social y político colonial que oponía a las regiones del mundo bajo las categorías de colonizadores/colonizados (Ibíd.), el desarrollo convirtió a todos los estados independientes en parte de una misma familia

2 Fue la fase monopolista del sistema capitalista, a través de la cual se desarrolló un sistema económico-comercial basado en el control de los recursos naturales del planeta por parte de los imperios de la época, gracias al sistema colonial (Cfr. Díaz Polanco, 1989). 
(Ibíd.); con la salvaguardia de que no todos éstos se encontraban en las mismas condiciones de desarrollo económico.

En este sentido, el término "subdesarrollo" aparece no solo como el calificativo para explicitar esta diferencia, sino también para legitimar una lógica secuencial de pasos a seguir para alcanzar el desarrollo (Ibíd.). La ideología de progreso, entonces tomará una forma institucional a través de la creación de organismos internacionales que concebirán programas y políticas de planificación y ejecución ${ }^{3}$ para suprimir esta brecha entre el subdesarrollo y el desarrollo.

De esta manera, la vieja estructura que antes dividía al planeta en términos de evolución racional, ahora pasaba a explicarse además en términos de crecimiento económico y desarrollo de la técnica, siendo fenómenos como la pobreza, la hambruna, la sobrepoblación, el analfabetismo, la mortalidad, entre otros los principales indicadores de subdesarrollo, que finalmente, llevarán a la construcción estereotípica de lo que se bautizaría como el "Tercer Mundo" (Cfr. Escobar, 1998). Bajo este discurso desarrollista, todos aquellos países y regiones del Tercer Mundo pasaron a ser parte de un "conocimiento especializado", que justificó una eminente lógica proyectivista de intervención, entendida ésta como programas estratégicos de transformación de prácticas sociales (previamente descalificadas), sustentados en conocimientos científicos especializados, legitimados por una autoridad de orden económico y/o político.

\section{EI desarrollo sostenible. Un modelo de la "lógica proyectivista de intervención"}

Casi tres siglos han pasado desde que la ideología del progreso ha liberado a los seres humanos de su "estado de naturaleza" y los ha encaminado "...lentamente en una dirección definida y deseable" (Ibíd.) de desarrollo económico. Sin embargo, para las últimas cuatro décadas del siglo $\mathrm{XX}$, este orden social, ya levantaba demasiadas sospechas con respecto a su validez; pues, pocos se contaban como los beneficios para una creciente población mundial empobrecida y muchos los daños que este sistema capitalista-industrial había causado a la naturaleza desde su axioma de crecimiento económico ilimitado.

Para pensadores como Herbert Marcuse (Habermas, 1999), este aumento de "racionalización" en el mundo, reflejado en el desarrollo de la técnica, implicó no necesariamente un incremento de la racionalidad humana per se, sino que en nombre de ésta se justificó una forma de dominio político oculto. A través de determinado uso de tecnologías y construcción de sistemas de reflexión se había hilvanado un "proyecto histórico social" (Ibíd.) que volvió racional el dominio de la naturaleza y el de los seres humanos en nombre de una “...vida más confortable” (Ibíd.).

\section{De la naturaleza sujetada al sujeto naturaleza.}

Para la década de los 70 del siglo XX, muchas comenzaron a ser las llamadas de atención a las actividades productivas industrializadas. Catastróficas eran las predicciones que se hicieron para el planeta, si no se consideraban la finitud de los recursos naturales. Daños irreversibles como la extinción de especies, agujeros en la capa de ozono, calentamiento global, se volvieron

3 Para 1958 Naciones Unidas creó el Fondo Especial de Naciones Unidas para el Desarrollo Económico (que se fusionó luego con el Programa Ampliado de Asistencia Técnica, creada en 1949, y que se denominará PNUD); además el Banco Mundial “...dedicará progresivamente la totalidad de sus recursos a los países del Tercer Mundo y para ello pondrá en pie, en 1956, la Sociedad Financiera Internacional destinada a favorecer las inversiones privadas; la Agencia Internacional de la Energía Atómica verá la luz en 1957. Finalmente se crearon los Bancos Regionales de desarrollo para África (1964) y para Asia (1966)" (Rist, 2002: 103).

4 Este concepto fue acuñado por los filósofos ilustrados del siglo XVIII para explicar el progreso humano y el "estado de naturaleza" era la condición más básica del ser humano a partir de la cual este comenzaría su progreso gracias al uso correcto de la razón (Cfr. Díaz-Polanco, 1989). 
parte de la preocupación de científicos, movimientos ambientalistas y de los mismos organismos internacionales que dejaron de considerar a la pobreza como el enemigo más acérrimo del desarrollo de los pueblos ${ }^{5}$; pasando a ser la crisis ambiental también parte de su agenda, ya que finalmente el deterioro de la naturaleza afectaba a países desarrollados y subdesarrollados por igual, pues todos estábamos en el "mismo barco".

En 1987, con la publicación del Informe "Nuestro Futuro Común", se definió por primera vez el principio de desarrollo sostenible $e^{7}$, que trajo al debate mundial dos puntos centrales de discusión: a) la relación entre desarrollo económico y medio ambiente; y b) la definición de políticas de acción específicas que ayuden a los países menos desarrollados a enfrentar los problemas de pobreza, deterioro ambiental y explosión demográfica, como aspectos estrechamente relacionados con el "tercer mundo" (Fisher, 1998).

Si bien, se pretendió rever y mitigar los niveles de contaminación de las actividades productivas en los países industrializados a través de convenios vinculantes, mecanismos de control y sanción; los países del "tercer mundo" tuvieron mayor protagonismo dado su "inexorable" vínculo entre pobreza y deterioro ambiental. Pues la premisa de tradición Brundtlandiana que afirmaba que la pobreza rural era uno de los factores principales que contribuían a la sobre-explotación de los recursos naturales (Cfr. Stallings, 2003), fue el engranaje de una creciente institucionalidad, -en la década de los 90-, en regiones como Asia, África, pero sobre todo en América Latina ${ }^{8}$ que reforzó la lógica de intervención de la cooperación internacional a través de proyectos de desarrollo, que esta vez incluyeron la conservación de la naturaleza.

Por otro lado, bajo los valores del desarrollo sostenible, la naturaleza desde su sentido cognitivo, tuvo la intención de trascender de una condición de objeto a una de sujeto desde un discurso hegemónico de conservación. Con la lógica proyectivista, se esperaba dar cabida a las distintas "racionalidades" (Cfr. Leff, 2000) de entendimiento de la naturaleza desde un sentido más pragmático, es decir, que en última instancia el objeto de intervención para la conservación en los países subdesarrollados serían las prácticas sociales con respecto a la naturaleza. Pues a través de éstas no solo que se harían los correctivos del caso con aquellas que no eran "amigables" con el ambiente; sino que además se potenciaría y se replicarían aquellas prácticas que demostraran ser conciliables con ella9.

5 En la Carta de las Naciones Unidad, se menciona que los pueblos inscritos a este organismo están decididos a "promover el progreso y mejorar sus niveles de vida dentro de una libertad mayor, a emplear las instituciones internacionales para la promoción del avance económico y social de todo los pueblos", siendo la pobreza un "enemigo común" de los pueblos libres, incluso "...más constante, más inminente que la sombra de la guerra" (Naciones Unidas, 1946).

6 El libro "Nuestro Futuro Común" (nombre original del Informe Brundtland) fue el primer intento de eliminar la confrontación entre desarrollo y sostenibilidad. Presentado en 1987 por la Comisión Mundial para el Medio Ambiente y el Desarrollo de la ONU, encabezada por la doctora noruega Gro Harlem Brundtland, quien trabajó analizando la situación del mundo en ese momento y demostró que el camino que la sociedad global había tomado estaba destruyendo el ambiente por un lado y dejando a cada vez más gente en la pobreza y la vulnerabilidad" (consultado en: http://desarrollosostenible.wordpress.com/2006/09/27/informe-brundtland/).

7 "...la capacidad de satisfacer las necesidades de las generaciones presentes sin comprometer la capacidad de las generaciones futuras para satisfacer sus propias necesidades" (Informe Brundtland, 1987).

8 Según la CEPAL (2002), se estima que entre 1990 y 1997 se financiaron 3489 proyectos de conservación, lo que representó una inversión de 3.26 mil millones de dólares. "De esta cifra total, un $54.7 \%$ fue invertido en América del Sur, $34.8 \%$ en Centroamérica y México, un $5.5 \%$ en el Caribe y un $5.1 \%$ en la región de América Latina y el Caribe en general" (Íbid: 104).

9 De acuerdo a Enrique Leff (2007: 288-289), el respeto de la diversidad cultural y de la identidad étnica favorecen el manejo sustentable de los recursos naturales, ya que éstas se basan en valores tradicionales de significación sobre la naturaleza. De ahí que las sociedades precolombinas, dice él, desarrollaron una relación íntima con la naturaleza, heredaron de las culturas andinas “... sistemas de cooperación y complementariedad [que les ha permitido] desarrollar sofisticadas estrategias de adaptación y producción sostenida". 


\section{El (eco) turismo...¿una alternativa de desarrollo sostenible?}

Si bien se reconoce un origen elitista del turismo, exclusivo de los jóvenes de las clases altas de Europa entre los siglos XVI y XVII que realizaban viajes por ultramar para conocer otras culturas exóticas (Muñoz de la Escala, 2007), será solo con el aparecimiento de la población proletaria en la Europa industrializada de principios del siglo XX que éste pasará a ser un fenómeno interesante de análisis desde un enfoque de la demanda ${ }^{10}$. Desde esta perspectiva los impactos de su vertiginoso crecimiento a partir de la década de los 50, -gracias al desarrollo e innovación de los medios de transporte ${ }^{11}$-, provocaron profundos impactos negativos ${ }^{12}$ a causa de lo que se denominó turismo de masas.

Sin embargo, la industria turística en el presente representa una de las actividades productivas emblemáticas de desarrollo sostenible, en parte por la amplia diversificación ${ }^{13}$ que ha alcanzado, gracias al desarrollo de las tecnologías de la comunicación motivados por los procesos de globalización; pero también por su intrínseca relación con la naturaleza, representada en un doble dimensión: como atractivo y como objeto de producción (Calderón, 2005).

La virtud del turismo de desencadenar procesos de oferta y demanda de bienes o servicios dentro del mercado de consumo, hace posible que las regiones subdesarrolladas -especialmente-, que requieren dinamizar su economía puedan hacerlo gracias al carácter intersectorial del turismo, que permite la diversificación y generación de empleo y exportaciones (Ibíd.), como a continuación lo ratifica la Organización Mundial del Turismo, OMT:

"El potencial del turismo para jugar un papel importante en la reducción de la pobreza es cada vez más reconocido por los organismos internacionales y los gobiernos nacionales. Su expansión geográfica y su capacidad para generar empleo son grandes ventajas que permiten a los habitantes pobres de remotas áreas rurales beneficiarse de esta actividad económica. Las estadísticas de la OMT muestran la fuerza con que crece la industria turística en los países en desarrollo. En 2005, las divisas recibidas por los países en desarrollo (los menos desarrollados, con ingresos bajos y medios bajos, o con ingresos medios altos) alcanzaron los 203 billones $\$ E U$. El turismo es uno de los mayores sectores de exportación en estos países, y la principal fuente de divisas en 46 de los 49 países menos desarrollados" ${ }^{14}$.

Por otro lado, la ventaja de ser una actividad no extractiva, le ha dado al turismo la posibilidad de redimirse más fácilmente que cualquier otra industria frente a los programas de conservación

10 La Escuela de Berlín, fue una de las primeras instancias académicas en la década de los 30 que tomó en consideración “...los flujos de turistas que acuden a ciudades y países y cuya presencia produce efectos diversos, básicamente económicos" (Calderón, 2005: 9).

11 El aparecimiento de los aviones de pasajeros después de la II Guerra Mundial, el bajo precio del petróleo, el aumento de la renta familiar, el aparecimiento de las vacaciones pagadas, el desarrollo de las comunicaciones, desarrollo de los medios de transporte terrestre, entre otros, facilitaron el traslado de personas hacia los lugares turísticos, siendo las playas los destinos preferidos (Sancho, 1998).

12 Los espacios físicos se redefinieron en función de la construcción de infraestructura y equipamiento de servicios para la actividad turística, aumentando así la presión sobre los recursos y el flujo de desechos evacuados al entorno, lo que causó contaminación de aguas, aire y suelo (Cañada y Gascón, 2007).

13 Por lugar: turismo de montaña, turismo de sol y playa, turismo de cruceros, turismo de casinos; por interés: turismo de patrimonio, turismo de naturaleza, turismo cultural, turismo de bienestar (salud), turismo deportivo, turismo de estudio, turismo de incentivo, turismo de investigación, turismo rural, turismo sexual, turismo gastronómico, turismo de visitas familiares; por valores: turismo responsable, turismo religioso, turismo místico turismo de ayuda humanitaria. Consultado en:

www.embajadadebrasil.org.do/media/conteudo/espanhol/turismo/ecotur/conceito/tturismo/apresent.htm; http://politicamas.blogspot.com/2006/08/turismo-tipos-de-turismo-actual.html; http://www.yoteca.com/pg/Informacion-de-tipos-de-turismo.asp

14 OMT, consultado en: http://www.unwto.org/step/about/sp/step.php?op=1, [acceso febrero 2008]. 
de la naturaleza, que no han tardado en sentir afinidad por la posibilidad de crear un círculo virtuoso de desarrollo gracias a éste, como a continuación podemos ver en el Gráfico $1^{15}$.

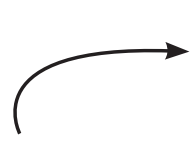

Conservación

de espacios naturales en países subdesarrollados
Naturaleza

en su estado más in situ

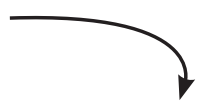

Motivación

turistica de los visitantes de países desattollados.
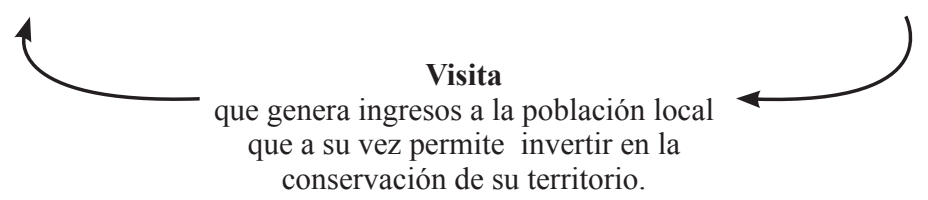

Gráfico 1. Círculo virtuoso del turismo sustentable

En el presente, el turismo con esta combinación de ventajas comparativas es considerado un sector clave dentro de la economía mundial que se encuentra en entera sintonía con la sostenibilidad del desarrollo. En la Conferencia Mundial de Turismo Sostenible llevada a cabo en Lanzarote, Islas Canarias (España) en 1995, con la estrategia turística mundial redactados en la Carta de Lanzarote, se aceptó definitivamente la existencia de:

“... los lazos de la sostenibilidad, la conservación y el desarrollo de los recursos, y el papel central del turismo para el desarrollo de muchas localidades a nivel de la geografía mundial y muy particularmente de los países menos desarrollados con una variada riqueza de flora, fauna, paisajes y elementos culturales" ( López, 2001: 208).

Con esta dimensión "enverdecida" de la industria turística, el (eco) turismo aparece entonces como el concepto operacionable del turismo sostenible que se define como el "...viaje responsable a zonas naturales que conserva el ambiente y sustenta el bienestar de la población local" (WWF, 2001).

Este turismo de naturaleza, que según investigaciones del PNUMA y el PNUD (2001), representa el $50 \%$ del turismo internacional, con un crecimiento anual de casi el $20 \%$, -a un ritmo mucho más rápido que toda la industria en su conjunto-, no solamente que fomentaría la delimitación jurídco-legal de los espacios naturales en áreas de reserva o parques nacionales para su conservación, sino que además su dinámica, lo disponía a convertirse en la industria civil más importante del mundo (Cevallos Lascuráin, 1993 en: Azócar de Buglass, 1995).

\section{Volviendo al "estado de naturaleza". La ventaja comparativa del "buen salvaje"}

Con la paradigmática introducción del principio de sostenibilidad en el desarrollo económico, muchas y crecientes fueron las propuestas de turismo a pequeña escala en sus más variados matices $^{16}$, fomentadas bajo la lógica proyectivista de intervención en las regiones subdesarrolladas. Sin embargo, no podemos dejar de mencionar que en el actual sistema de mundialización del

15 Elaboración de la autora, con referencia de Cordero, 2006.

16 Llamándose turismo comunitarios, turismo vivencia, agroturismo, turismo de naturaleza, turismo de sendero, turismo responsable, etc. 
mercado, la industria turística tiene un punto más a su favor: la desterritorialización de los lugares turísticos, pues ante el declive del estado nación frente a la emergencia de un estado red (Cfr. Castells, 2003), consecuencia de los procesos de globalización, el territorio ha dejado de estar delimitado por las categorías nacionales, para insertase a los circuitos de mercado a través de sus ventajas comparativas.

Por lo tanto, más allá de estar representado en una región, país o comunidad, el desarrollo territorial del potencial endógeno (Canzanelli, 2004), ha pasado a ser parte importante de las agendas sectoriales que identifican y resaltan aquellas particularidades locales (étnicos, culturales, sociales, ecológicas), que pueden ser atractivas y consecuentemente competitivas. Siendo para el caso del turismo su mayor ventaja la construcción de una naturaleza socializada.

Con este trasfondo, los parques nacionales de África Oriental, Asia (Nepal) y América Latina (Costa Rica, Ecuador), adquirieron un valor agregado distinto, que trascendía aquella visión fragmentada, promovida sobre todo en la década de los 80 , de una naturaleza delimitada "virgen", “exótica" y "salvaje"(Cfr. Gudynas, 2003), conservada en sus condiciones más in situ por la normativa ambiental.

La existencia de población cercana a sus áreas de amortiguamiento, se distinguió entonces como una ventaja de participación ciudadana para la edificación y manejo de infraestructura turística ecológica que al mismo tiempo que contribuía al manejo sostenible de estos parques, motivaba actividades económicas para la población que se responsabilizaba de su territorio por ser éste un recurso de desarrollo local.

Gracias, al dinamismo económico generado por el pago de entrada a las áreas de reserva, alojamiento, alimentación, guías turísticos, entre otros, se promovería beneficios indirectos derivados de los primeros, denominados éstos como "efectos multiplicadores en la economía local ${ }^{17}$ " (Azócar de Buglass, 1995) de aquellas áreas remotas que históricamente han tenido pocos beneficios de los programas de desarrollo económico (Cfr. Wunder, 1996).

Este protagonismo de la población local, no solo significó para los técnicos, la posibilidad de una revalorización social y cultural de las prácticas humanas con respecto a su entorno (Cordero, 2006); sino que, además esta vinculación entre cultura y territorio, ganaba mayor interés dentro del discurso (eco) turístico que resaltaba esta "relación dialógica" (Leff, 2000); sobre todo en aquellos lugares donde existían pueblos y comunidades indígenas relacionados ancestralmente con su espacio natural.

Bajo esta matriz, se avivó la visión del "buen salvaje 18 ", de estas poblaciones, calificadas como “...la mejor guía para entender el entorno y gestionarlo" (Gudynas, 2003: 26) contraponiéndolas con las concepciones occidentales que poco respeto habían demostrado por la naturaleza.

Esta incorporación del "buen salvaje" al turismo de naturaleza dio como resultado la promoción de un turismo étnico, sobre todo para los bosques húmedos de Brasil, Perú y Ecuador, que motivaron iniciativas encaminadas justamente a satisfacer al turista interesado en conocer e interaccionar con grupos humanos exóticos (Cfr. Oakes, 2000, en Pereiro et al., 2007).

Para autores como Pereiro (2007) este tipo de turismo, apuntó a consolidar la imagen de estas comunidades como "pueblos testigos" (Cfr. Ribeiro, 1977, en Pereiro et al., 2007), encaminadas a "...recrear su identidad y su espacio por medio de la autorepresentación a otros grupos humanos y de la conversión de su espacio en una especie de zoológico humano indigenizado" (Pereiro, et al., 2007: 20).

Desde esta perspectiva, el turismo sostenible (re) construye la relación naturaleza/seres

17 Servicios, infraestructura, empleo, etc.

18 Jean Jacques Rousseau (1712-1778), contrario a la propuesta de Hobbes, consideraba que el ser humano en su estado "natural" era feliz, bueno y libre. Cercano a la naturaleza, guiado por su amor a si mismo, Una condición que desapareció cuando éste paso a ser parte de la vida en sociedad (Cfr. http://www.cibernous.com/autores/rousseau/ teoria/biografia.html). 
humanos desde un sentido ontológico para diferenciar aquello que está opuesto a la civilización, pero a diferencia del siglo XVIII ésta condición no es un estado exclusivo de retraso o falta de racionalidad humana, sino que bajo las dosis adecuadas de "salvajización" y "exotización", es una ventaja tanto para la conservación del medio ambiente, como para los turistas interesados en conocer lo excepcionalmente distinto a ellos, es decir, al ser humano en su "estado de naturaleza" dentro de una lógica de mercado.

\section{El Ecuador, un territorio privilegiado para el (eco) turismo.}

Podríamos decir, que a pesar de que Ecuador es parte de una región calificada como "subdesarrollada", este es un país que ha contado con mucha suerte. Su privilegiada ubicación geográfica, no solo que lo ha incluido como parte de los países más megadiversos ${ }^{19}$ de la región y del planeta; sino que además sus características socioculturales lo identifican como un territorio con muchas ventajas comparativas para el (eco) turismo y el desarrollo local económico.

Aunque las Islas Galápagos fueron por mucho tiempo la carta de presentación turística de este país, ahora son diversas las alternativas que el Ministerio de Turismo ha podido inventariar como "productos turísticos" dentro de su Plan de Marketing (PLANDETUR 2020, 2007). La posibilidad de hacer exclusivamente turismo de naturaleza (visita parques nacionales), turismo cultural (artesanías, fiestas populares, medicina ancestral), o combinar las dos al mismo tiempo es quizás la mayor ventaja de este territorio de apenas $260 \mathrm{mil} \mathrm{Km} 2$.

Los casos de estudio que vamos a introducir son parte de esta particularidad geográfica y sociocultural del Ecuador, que pese a compartir un territorio histórico en común, sus diferencias son marcadas a la hora de considerar sus respectivas propuestas (eco) turísticas, pues su relación con el discurso del desarrollo ha dependido en gran medida del imaginario bajo el cual se ha construido históricamente cada una de las regiones del país.

\section{San Clemente, una comunidad en la provincia de los lagos}

San Clemente es una comunidad indígena de 552 habitantes ${ }^{20}$, localizada al oriente de las faldas del volcán Imbabura (4600 m.s.n.m), dentro del cantón Ibarra, en la parroquia rural La Esperanza. El 70,51\% de la población en esta parroquia es indígena kichwa hablante. De acuerdo al censo del 2001, la pobreza por necesidades básicas insatisfechas fue del 84,7\% (SIISE 4.5).

En el pasado, esta comunidad fue parte de la hacienda San Clemente, que hasta la reforma agraria fue el principal eje de subsistencia de los indígenas que trabajaron en ella como huasipungeros. A través de un precario sistema de endeudamiento los antepasados de estas familias se vieron atados a este por varias generaciones, como a continuación podemos apreciar en el siguiente testimonio:

\footnotetext{
"Esta parte era huasipungo yo solito vivía aquí de ahí hacienda era todito esto, [el hacendado] no quería entregar los huasipungos querían entregar poco, peleando nos dieron al otro lado de la quebrada. [En el tiempo de hacienda] no había plata, se sembraba trigo, cebada hasta arriba el lindero. [Antes] si teníamos puercos, borregos, vacas pero ya acabamos. El capataz tenía escondido animales del patrón y cuando se perdían los animales nos cobraban a nosotros" (Entrevista, C.G, 2007).
}

Este sistema intensivo de producción agropecuaria, contribuyó en gran medida a la deforestación de los bosques húmedos andinos, que como menciona Hidalgo (2007) comenzaría

19 En Latinoamérica se encuentran 6 de los 19 países más biodiversos del mundo: Brasil, Colombia, Ecuador, México, Perú y Venezuela. En éstos se concentra un alto índice de especies endémicas (Cfr. CEPAL y PNUMA, 2002).

20132 familias en total. 
desde la segunda mitad del siglo XVIII con la expansión de la frontera agrícola, de ahí que el territorio de San Clemente se asiente sobre una pendiente muy erosionada. Y aunque la reforma agraria dio fin a la hacienda serrana como el sistema imperante de explotación del trabajo precario indígena, esto no significó necesariamente el mejoramiento de sus condiciones de vida. En la actualidad, esta comunidad se enfrenta a la extrema minifundización de tierras y a la escasez de agua para riego, lo que ha limitado el cultivo de productos, siendo el trigo y la papa los monocultivos característicos de esta zona.

Las comunidades que conforman la parroquia de La Esperanza tienen una tradición migratoria $^{21}$, siendo la principal razón las motivaciones laborales (43.59\%), aunque un porcentaje representativo de la población se dedica a la agricultura $(36.9 \%)$ como la principal rama de actividad. La construcción (15.03\%) también es otra importante rama de ocupación, de ahí que el trabajo de albañilería sea una actividad frecuente, sobre todo entre la población masculina; mientras que las mujeres que han logrado insertarse en el mercado de trabajo lo han hecho dentro de las actividades domésticas.

\section{El turismo vivencial}

San Clemente, comenzó a sondear la posibilidad del turismo desde el año 2000, después de un estudio de factibilidad realizado por una voluntaria extranjera. Sin embargo fue solo hasta un viaje a Noruega realizado por un dirigente ${ }^{22}$, quien pudo apreciar el proyecto turístico de los indígenas Samis, que se concretó el turismo en esta comunidad.

Al principio, fueron tres las familias que optaron por ofertar un turismo comunitario basado en la convivencia familiar en la comunidad. Actualmente son 18 familias en total las que forman parte de esta propuesta turística, que reciben al año un promedio de 60 familias extranjeras, de origen europeo en su mayoría.

Para esto, el paisaje arquitectónico, se ha modificado en San Clemente con la construcción de cabañas, estilo rústico, adosadas a sus viviendas para recibir a los visitantes, quienes llegan a compartir la cotidianidad con sus anfitriones. Como parte de los servicios turísticos que se oferta están los bordados realizados por las mujeres, las clases de quichua o de bordado, los paseos al monte Imbabura, presentaciones del grupo de música tradicional, y en fechas específicas fiestas como la del Inti Raimi.

Esta propuesta, a decir de sus participantes, "gestada desde adentro" (P.C. entrevista, 2007), bien puede ser parte de las iniciativas exitosas del turismo sostenible, que ha previsto dentro de su dinámica la inclusión de familias que al no tener los recursos para construir una cabaña para turistas puedan recibirlos en sus propias casas a un costo de hospedaje menor. Asimismo, se ha comenzado a generar redes incipientes de servicios (comida, transporte, etc.) no solamente a nivel de la comunidad sino de otras comunidades vecinas.

La reforestación de las faldas del monte Imbabura, también se cuenta como una de las iniciativas ecológicas lideradas por el cabildo. Se han cultivado especies que aumenten la fecundidad del suelo con el propósito de que algún día se pueda cultivar especies de árboles frutales. A lo largo de una quebrada seca se han sembrado plantas de uso doméstico y medicinal, la cual puede ser visitada por los turistas a través de un recorrido guiado.

Por otra parte, la imagen de la comunidad ha mejorado progresivamente en el tema de la recolección de basura, arreglo de vías, equipamiento de infraestructura, recuperación de

21 Históricamente, la Sierra ha sido la región del Ecuador con las mayores tasas de emigración por trabajo, en el caso de Imbabura vale la pena anotar que su cercanía geográfica con la provincia de Pichincha, -concretamente con Quito-, ha favorecido al desarrollo de un tipo de migración estacional, que ha evitado la caída de su densidad demográfica, que registraba para el 2001 la tasa más alta de toda la Sierra Norte, con el 74.6 (INEC), con una tasa de crecimiento poblacional en el área rural del $2.10 \%$ (Ibídem).

22 Como parte de la comitiva que representaba a la ECUARUNARI en un encuentro de pueblos indígenas. 
patrimonio arqueológico ${ }^{23}$; pero sobre todo con la prohibición de expendio de licor, considerado como uno de los mayores logros para la comunidad, pues los índices de alcoholismo entre la población masculina eran alarmantes.

Entre los beneficios de esta actividad, está la posibilidad de disminuir los índices de migración masculina con la participación de los jóvenes como guías al monte Imbabura o a la Reserva Cotacachi-Cayapas. Las mujeres por su parte, tienen la alternativa de vender sus tejidos directamente al visitante a través de la tienda comunitaria y de complementar estos ingresos con el costo de hospedaje, alimentación, clases de bordado y de kichwa a sus visitantes.

\section{El turismo de naturaleza en El Recuerdo}

El recinto El Recuerdo, es un pequeño poblado rural, localizado en el cantón Vinces, provincia de Los Ríos, que se compone de aproximadamente 47 familias campesinas distribuidas a lo largo de la entrada y alrededor del humedal Abras de Mantequilla.

Según testimonios de los más ancianos, se estima que el territorio donde ahora se asienta este recinto comenzó a poblarse hace aproximadamente 100 años, cuando dos hermanos compraron tierras, que luego pasaron a ser tierras de herencia, de ahí que en algún punto todos sus habitantes comparten un lazo de parentesco. Esta población campesina-montubia se dedica principalmente a las actividades agrícolas, siendo los cultivos de maíz y de arroz los productos más comercializados.

El Recuerdo fue tempranamente parte de los procesos de modernización de la provincia, intensificados por el boom bananero durante la década de los 50, lo que motivó la creación de rutas y caminos de primer y segundo orden que facilitaron la comunicación; así como el uso de medios de transporte como la lancha, el remolque y el automóvil. Sin embargo esta modernización terminó siendo intermitente para este recinto, en el que apenas en la década de los 90 se implementó el servicio de luz eléctrica; mientras que hasta el presente todavía no cuentan con servicios de agua potable y alcantarillado. El 70\% de sus pobladores hace uso del agua subterránea, o "agua de poza" como se la conoce comúnmente, tanto para el autoconsumo como para el riego de cultivos.

\section{Un proyecto de desarrollo para el humedal}

El humedal de 22.500 hectáreas conocido localmente como "Las Abras", es un importante eje articulador tanto de la vida social como productiva. Con sus dos momentos climáticos bien diferenciados: verano e invierno, este sistema lentico es un contenedor importante de agua dulce que durante la época de invierno, con el aumento de su caudal ${ }^{24}$, alimenta tanto las aguas superficiales, favoreciendo las actividades de pesca y transporte; como las aguas subterráneas utilizadas para el riego de los cultivos de temporada. Mientras que, en verano (junio), cuando éste se seca casi por completo, pone a disposición las tierras bajas listas para el cultivo de arroz veranero.

Dada su prolija fertilidad, las Abras han experimentado históricamente una intensa presión de sus suelos, que han sido ampliamente ocupados por los monocultivos, (arroz, pastos y maíz) y que en el presente han llevado a una crónica deforestación de esta zona, siendo precisamente los cantones que la circundan los que presentan los niveles más altos en sus áreas de producción agropecuaria de toda la provincia: Vinces (99.23\%), Pueblo Viejo (97.51\%) y Baba (99.64\%) (CISMIL, 2006).

23 Tolas truncadas de posible origen Caranqui.

24 Sus aguas desembocan en el río Nuevo, que a su vez desembocan en el río Vinces que libera sus aguas en el río Babahoyo (Cfr; FUNDAR; 2002). 


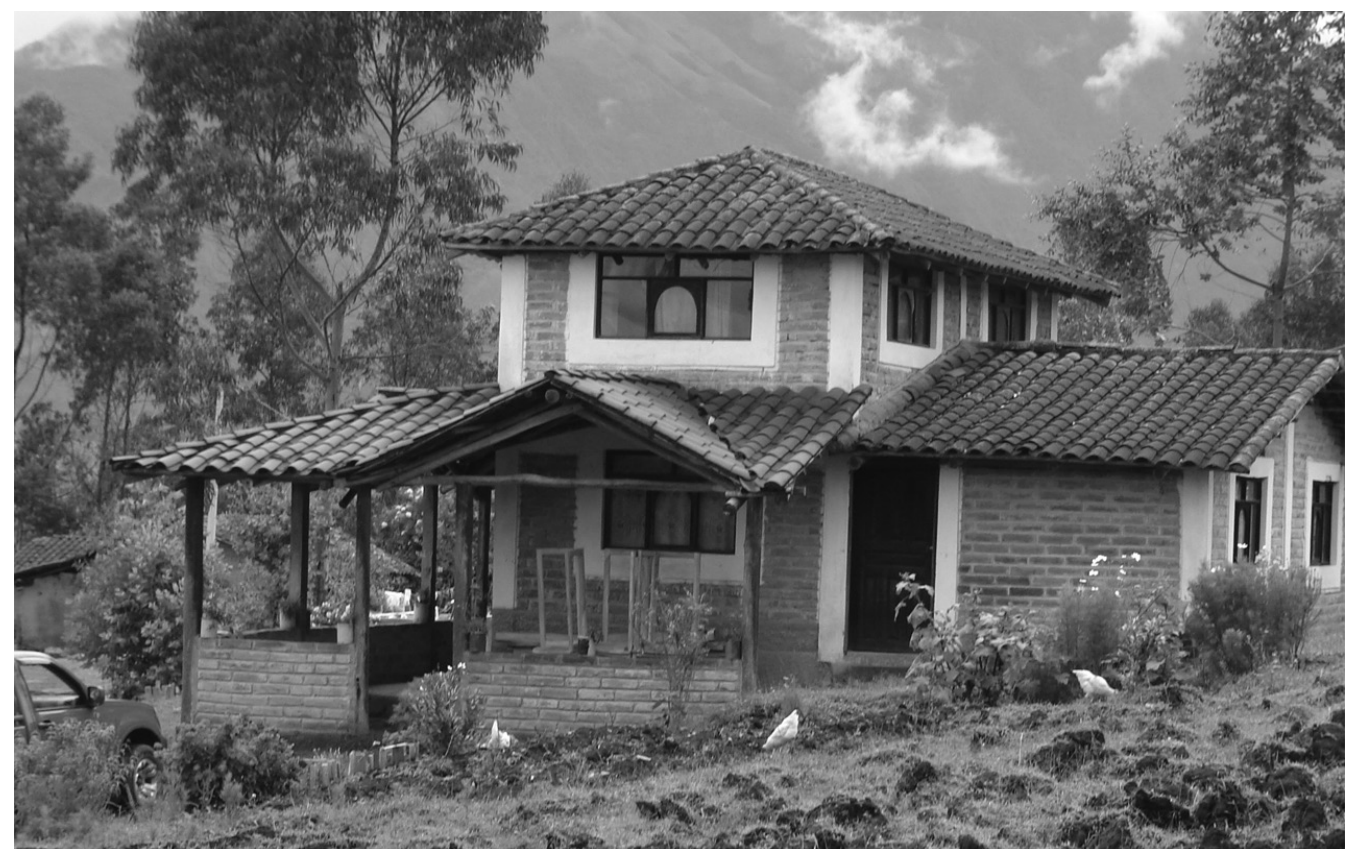

Figura 1. Cabaña construida en la comunidad de San

Clemente para Recibir turistas EXTRANJeros.

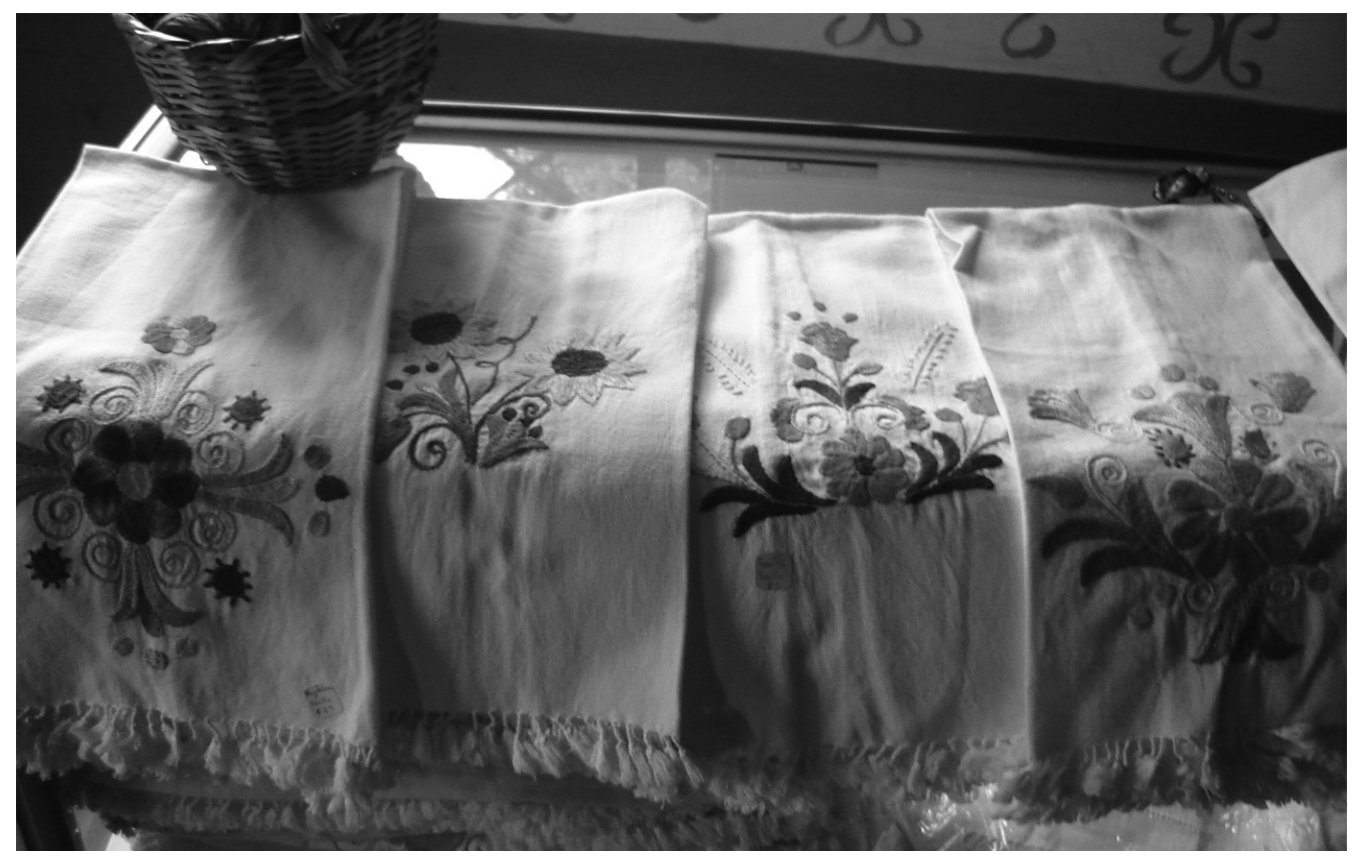

Figura 2. Bordados elaborados a mano por las mujeres de la comunidad San Clemente, expuestos en la tienda COMUNITARIA. 
Según juicio de una técnica local, se le abrió muchas oportunidades en el 2000 cuando fue declarado sitio RAMSAR ${ }^{25}$ dada su sensibilidad ecológica, pues este ecosistema está constituido de pequeños remanentes dispersos de bosques secundarios, bosques plantados, pastizales y cultivos, en el que se "... han reportado un total de 127 especies de aves en el humedal y los bosques circundantes. Alberga además 20 especies acuáticas congregatorias" ${ }^{26}$.

Con su declaratoria como sitio RAMSAR, este humedal pasó a ser parte de un estatus diferenciado en la agenda de conservación. Todas aquellas iniciativas previstas para tal propósito encontraron resonancia en proyectos de desarrollo sostenible como el propuesto por PROLOCAL en el 2001, con el mejoramiento del sistema de riego para el cultivo de cacao ${ }^{27}$, complementado con un componente de turismo y conservación y el de FUNDAR $^{28}$ en el 2002, denominado: "Apoyo comunitario a la conservación del Humedal Abras de Mantequilla en el cantón Vinces, Provincia de los Ríos". Éste último, que es en el que nos interesa enfocarnos, fue un proyecto presentado al Programa de Pequeñas Donaciones-PPD ${ }^{29}$ de Naciones Unidas, bajo dos objetivos estratégicos de ejecución:

1. Reducir las presiones antrópicas sobre los ambientes lénticos y de tierra firme del humedal a través de alternativas productivas con enfoque ecosistémico y de sustentabilidad social, económica y ambiental, tales como turismo hacia la naturaleza.

2. Institucionalizar la propuesta comunitaria de manejo de recursos naturales desarrollados en el proyecto (Fundar, 2002-2004)

Auspiciado finalmente por el PPD por un monto total de 50 mil dólares, este proyecto categorizó bajo cuatro componentes (reforestación, agroecología, educación ambiental y turismo) los puntos prioritarios de intervención en los recintos de: El Recuerdo, Abanico, Piedad, Loma Colorada, Estero Lagarto y Amalia, con un anexo posterior de los recintos La Luz y Playones (Ibíd.).

Con el componente de agroecología, se esperaba contribuir con alternativas ecológicas a las prácticas agrícolas causadas por la persistencia de los monocultivos, que ha fomentado el uso excesivo de plaguicidas como el glifosato ${ }^{30}$, contaminación de aguas, sembríos sin rotación ni descanso del suelo, intensiva deforestación y consecuente pérdida de especies de flora y fauna, entre los más importantes.

25 Convención relativa a los Humedales de Importancia Internacional especialmente como Hábitat de Aves Acuáticas.

26 En: http://www.darwinnet.org/docs/Ibas_RT/EC024.pdf [consultado febrero 2009]

27 Con este proyecto que duró un año aproximadamente, se creó la Federación de trabajadores agrícolas del cantón Vinces- FEDETACV, una organización campesina de segundo grado, con la que se esperaba aglutinar a todas las organizaciones de base circundantes al humedal. Esta organización fue la encargada de realizar la gestión de la compra de bombas para riego con un porcentaje de recursos entregados por PROLOCAL y con una contraparte económica por parte de los campesinos interesados en adquirir estas bombas. FUNDAR fue la entidad que concedió crédito a las personas interesadas.

28 La Fundación para el Desarrollo Agrícola Rural FUNDAR, es una entidad privada creada en abril de 1992, cuyas líneas de acción involucran la promoción de la producción agropecuaria, crédito, asistencia técnica y apoyo en la creación de cooperativas locales de ahorro y crédito (Fundar, 2002-2004).

29 "El Programa de Pequeñas Donaciones (PPD) forma parte del Fondo para el Medio Ambiente Mundial (PPD/ MFAM), que es un mecanismo de apoyo financiero para proteger el medio ambiente mundial y está destinado a países en vías de desarrollo. [...] Este programa está orientado a dar respuestas locales a los problemas ambientales mundiales como son: la conservación de la biodiversidad, iniciativas que busquen atenuar los efectos del cambio climático, la desertificación, que trabajen en ecosistemas acuáticos compartidos entre varios países (aguas internacionales) y la sensibilización ciudadana para lograr disminuir el uso de Contaminantes Orgánicos Persistentes (COPs)" (Varea, s/f: 34).

30 "El glifosato (N-fosfonometilglicina, C3H8NO5P, CAS 1071-83-6) es un herbicida no selectivo de amplio espectro, desarrollado para eliminación de hierbas y de arbustos, en especial los perennes. Es un herbicida total. Es absorbido por las hojas y no por las raíces. La aplicación de glifosato mata las plantas debido a que suprime su capacidad de generar aminoácidos aromáticos" en: http://es.wikipedia.org/wiki/Glifosato , [acceso: febrero, 2009]. 
Se implementaron entonces huertos hortícolas en la Amalia, el Recuerdo, Loma Colorada y Piedad; y además se construyó una planta procesadora de abono orgánico en El Recuerdo, con el fin de capacitar a los campesinos de la zona en la elaboración de biol ${ }^{31}$ mejorado, compost y repelentes naturales de insectos. Se sembraron árboles a lo largo de los bordes del humedal, se crearon pequeños viveros forestales con cacao nacional para reproducir cultivos asociados con otras especies como el guachapelí, cedro, laurel, distribuidos en varios recintos (FUNDAR 2002-2004).

Con todo este trabajo, complementado además con las charlas en educación ambiental previstas en el proyecto, se intentó cubrir todos aquellos elementos que previamente se había considerado como factores de riesgo para la conservación del humedal, sin embargo, todavía han quedado pendientes temas como la introducción de ganado, el manejo de la basura, la caza de animales silvestres y la disminución de agua de poza utilizada para riego.

En lo que se refiere al componente de turismo, se llevó a cabo un programa de capacitación de guías locales y la construcción de una cabaña ecológica como actividades concretas. El Recuerdo fue el recinto donde se ejecutaron estas actividades, pues es la entrada principal al humedal donde existe un pequeño malecón y en el cual se llevan a cabo cada año las populares regatas campesinas ${ }^{32}$.

Dentro de la capacitación para el turismo en la zona, sus participantes recibieron taller en lo que se refiere a trato al cliente, información del humedal de interés para el turista para el caso de recorridos guiados, mantenimiento de servicios (hospedaje, alimentación, etc.), entre otros.

La ASEC ${ }^{33}$, es otro actor que ha trabajado en la zona, sobre todo con gente del Recuerdo desde el 2005, a propósito del convenio que este organismo no gubernamental firmó con el Ministerio de Turismo para regular y certificar la actividad turística en el país a través de la implementación de la Norma Técnica de Ecoturismo ${ }^{34}$ (2003), una herramienta de evaluación para controlar que las actividades turísticas se enmarquen en los principios reglamentarios de funcionamiento empresarial. La metodología de trabajo, se ha basado en la socialización de experiencias turísticas en distintos lugares del país, en los cuales han participado el presidente y un joven del recinto que han viajado a conocer otras iniciativas.

\section{Entre la "re-funcionalidad" étnica en la Sierra y la productividad agrícola de la Costa}

No podemos analizar el presente de los proyectos de (eco) turismo en San Clemente y El Recuerdo, sin remitirnos antes a la construcción histórica de la región Costa y Sierra. El proyecto de estado-nación al comienzo del XIX hundió sus raíces en la idea progreso de occidente y a partir de este dependió en gran medida la creación e implementación de políticas y programas de desarrollo y modernización en cada una de estas regiones del país.

31 El biol, es un abono orgánico compuesto de diferentes guanos que tienden a fermentar durante dos o tres meses en un recipiente sellado.

32 Estas regatas se festejan en el mes de abril, después de semana santa. Esta manifestación festiva de tradición montubia es organizada por gente de El Recuerdo. Con un duración de dos días, para estas fiestas se contrata orquestas en vivo, se realizan bailes nocturnos, carrera de botes (a remo y motor), elección de reina.

33 La ASEC fue fundada en 1992 como una organización sin fines de lucro. Actualmente son parte de actividades conjuntas con el Ministerio de Turismo para llevar adelante el plan de Tour que consiste en la planificación de desarrollo de turismo sostenible con perspectiva al 2020, en donde se busca que todos los involucrados sean parte de este proceso (Entrevista funcionario ASEC, 1997).

34 Esta Norma es parte de los procesos de certificación para la sustentabilidad turística que fueron impulsados en América Central y América Latina gracias al programa que se implemento en Costa Rica desde 1993 siendo sus ámbitos de evaluación: el natural, los servicios , el cliente externo y estándares socioeconómicos. En el caso del Ecuador los parámetros de evaluación se han dividido en: calidad ambiental, calidad sociocultural y calidad en servicios (Cfr. Azevedo, 2007). 


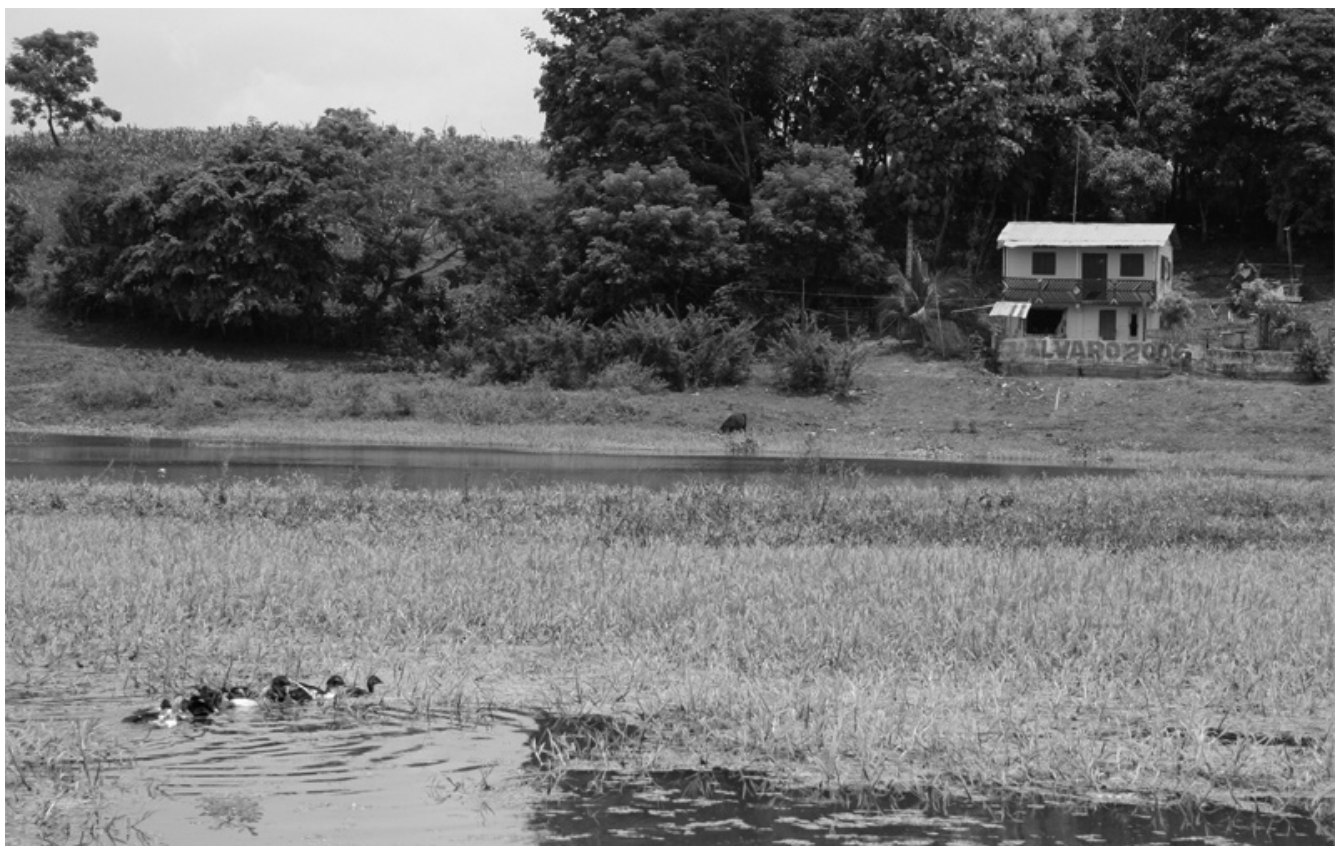

Figura 3. El humedal Abras de Mantequilla en verano, vista desde el recinto El

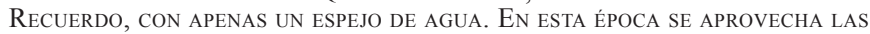
TIERRAS INUNDABLES PARA SEMBRAR ARROZ VERANIEGO.

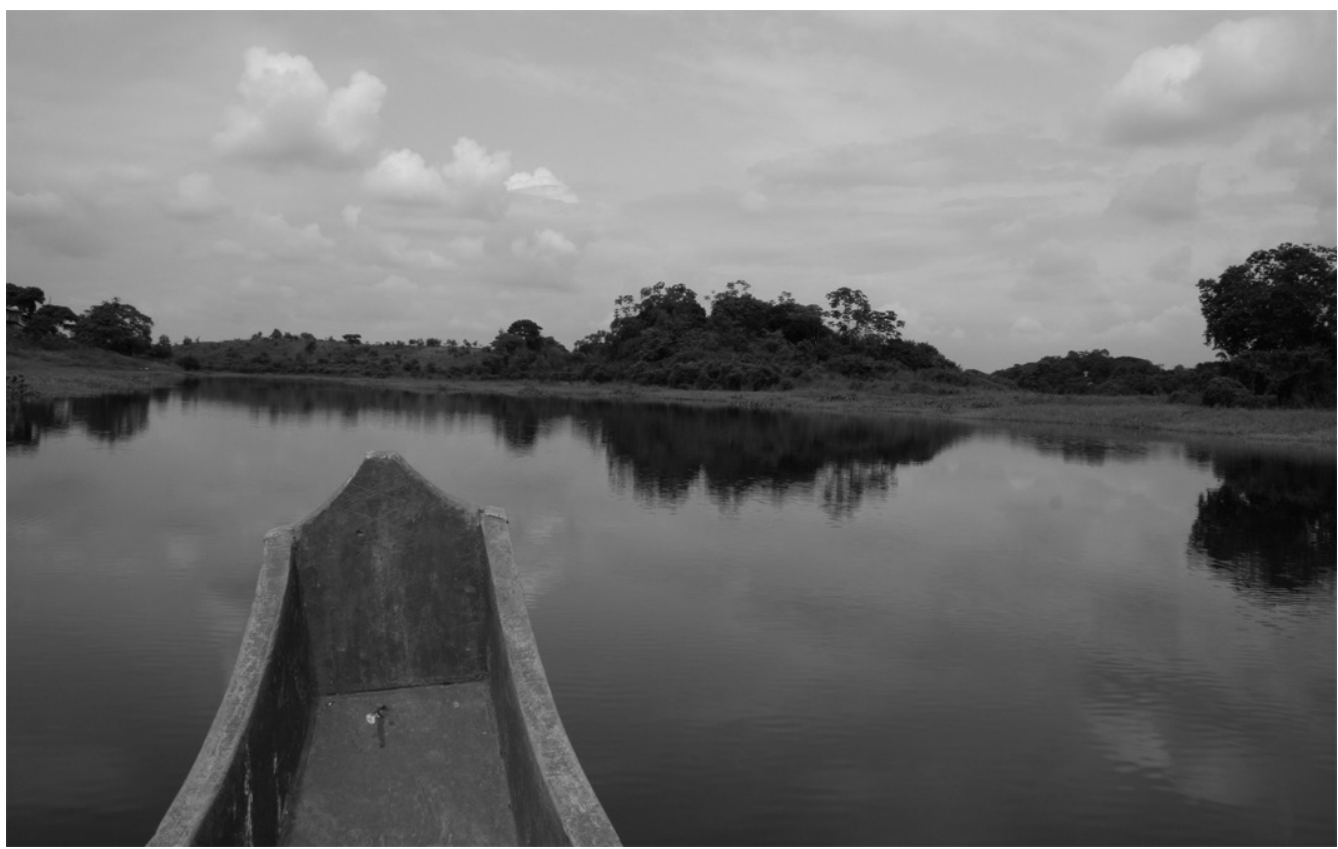

Figura 4. El humedal Abras de Mantequilla en invierno, vista desde el recinto El RECUERDO, ÉPOCA EN QUE LA GENTE PREFIERE TRANSPORTARSE POR CANOA. EL RECORRIDO ES MÁS CORTO QUE POR LA CARRETERA. 
Para mediados del siglo XX, en el caso de la Sierra -en particular de la sierra centro norte-, los programas de desarrollo tendieron a enfocarse en la "reactivación" de la producción agraria tomando como una variable central de intervención el tema étnico, pues después de la época colonial, donde la explotación de los recursos naturales y de la mano de obra indígena fue intensiva, el sistema hacendatario tradicional que se consolidó en esta zona a mediados del siglo XIX, se encargó de alimentar la imagen del indígena bajo los valores sociales de pobreza y baja productividad.

En el marco del desarrollo rural de mediados del siglo XX, la Misión Andina fue uno de los proyectos en la sierra centro-norte, que bajo el epígrafe de "desarrollo rural integral", se puso en el centro de intervención a las formas de organización social de las poblaciones indígenas como instrumentos susceptibles a ser "....refuncionalizados, reorientados y convertidos en instancias de la sociedad indígena de cara a la adopción de un determinado proyecto modernizante" (Bretón, 2001: 63).

De esta manera, el paradigma de "desarrollo de la comunidad" fue la piedra angular a partir de la cual se difundió la capacitación técnica y la infraestructura con fondos de la Misión Andina, que para 1958 pasó a ser política nacional tomando el nombre de "Plan Nacional de Incorporación del Campesino", y fue en la provincia de Imbabura, después de Chimborazo (36\%), en donde hubo mayor cobertura (23\%) de acción entre las comunidades (Cfr. Martínez, 2000).

Con este panorama epistémico previo, los procesos de reforma agraria emprendidos por el Estado ecuatoriano a partir de 1964 partían no solamente de una caracterización cualitativa y cuantitativa de lo rural en términos de retraso, sino que además la eficiencia de la productividad sería el eje rector de las políticas sociales de reforma. Así, los programas de redistribución de la tierra no terminaron de eliminar el monopolio de este recurso por parte de las haciendas; sino que, por el contrario se reiteró bajo la lógica de eficiencia que los terratenientes mestizos eran los llamados a representar el símbolo de modernidad del país, “...dada su propensión a utilizar técnicas y maquinarias superiores...[éstos serían] más eficientes que los campesinos, aún si usaban menos tierra" (Acción 1979, en Pallares, 1999: 162).

Esta superioridad racial implícita, ponía en enorme desventaja a los indígenas de la sierra, a quienes se les terminó de entregar las tierras menos productivas en comparación con las que siguieron concentrando las emergentes élites mestizas, justificando la construcción social de lo indígena como "no productivo" y por tanto "... carente del espíritu capitalista y consecuentemente, destinado a permanecer en los niveles más bajos de la producción” (Pallares, 1999: 165).

A finales de los 70 y comienzos de los 80 , programas como el FODERUMA ${ }^{35}$ condensaron los valores del desarrollo rural en la sierra centro-norte del Ecuador, pues con fondos tanto nacionales como internacionales (ONU, OIT, BID) se esperaba "...elevar la calidad de vida de los grupos marginados y estimular el desarrollo de prácticas culturales y productos endógenos" (Pachano, 1989).

Hasta aquí, dos momentos se diferenciaron, al tiempo que intentaron converger en los programas de intervención en la sierra centro norte: por un lado, estaba toda la infraestructura que representaba un nivel de desarrollo material de la población indígena campesina (escuelas, centros de salud, vías de acceso, sistema de alumbrado, servicios de agua, etc.) que los pondría en las mismas condiciones que el resto; y por otro, estaba la aceptada diferencia de sus formas de organización con enormes posibilidades de ser potencializadas para su desarrollo, sobre todo agropecuario.

Por el contrario para el caso de la región costa, y de provincias como la de Los Ríos específicamente, los procesos de desarrollo y modernización se articularon en función de

35 Fondo de desarrollo rural marginal, creado en 1978 como un mecanismo de asignación selectiva de liquidez, dirigido por el Banco Central del Ecuador, para canalizar recursos financieros y técnicos, nacionales e internacionales, hacia los sectores campesinos marginados (Pachano, 1989). 
procesos previos de agro-producción que comenzaron a mediados del siglo XIX con el boom cacaotero -siendo su principal centro de producción la zona de Vinces- y que continuaron hasta mediados del siglo XX con el boom bananero. Lo que le dio a la región Costa un plus como la fuente de producción agrícola más importante del país, colocándola entonces como la región que bien podía liderar el desarrollo del Ecuador gracias a la consolidación de un mercado exportador de materias primas.

Esta imagen de la Costa tomó forma durante el gobierno de Galo Plaza Lasso (1948-1952), donde se fomentó la construcción de carreteras y la modernización de los puertos ${ }^{36}$ en esta región, así como la facilidad de créditos que esperaban aumentar la expansión de la superficie sembrada (Larrea, 2006). Con todas estas políticas, la migración masiva sierra-costa, se aceleró junto con los procesos de urbanización y “...en 1950, cuando se realizó el primer censo de población, un $40.5 \%$ de los 3.2 millones de ecuatorianos ya habitaban la llanura costera, donde se habían establecido las principales plantaciones de exportación" (Acosta, 2001: 105).

En este marco emblemático de progreso económico, la fertilidad de los suelos de provincias como Los Ríos adquirieron enorme reconocimiento y valor, fomentando así desde el Estado ecuatoriano la colonización de estas tierras para el trabajo exclusivo de producción agrícola. De este modo, la concepción del espacio de la provincia de Los Ríos, sus recursos naturales, el trabajo humano, las relaciones sociales y demás se construyeron dentro de esta racionalidad productiva gracias a la fertilidad de sus suelos, que muy poco ha variado a través del tiempo.

\section{Entre el "capital social" y la fertilidad de la tierra. Una diferencia para la construcción social de la pobreza}

Para la década de los 90, con el levantamiento indígena producido en el Ecuador, no solo se puso en evidencia a un Estado excluyente y la lucha de grupos sociales por su derecho al reconocimiento social y político, sino que además lo étnico, -que hasta entonces se había remitido casi exclusivamente al plano de la producción agraria-, fue resignificado, y pasó a ser parte de un discurso de la diferencia y la revalorización cultural (Viola, 2000, en: Bretón, 2001).

Este hecho histórico, que filtró la conciencia internacional, motivaría más tarde la implementación de programas y proyectos cuyo propósito fue el de contribuir al desarrollo rural desde las bases en un marco de reconocimiento identitario, siendo la manifestación más destacada de este objetivo el Proyecto de Desarrollo de los Pueblos Indígenas y Negros del Ecuador-PRODEPINE ${ }^{37}$ (Bretón, 2005), como “...una de las tentativas más ambiciosas y mejor dotadas presupuestariamente en materia de desarrollo rural en Ecuador" (Íbid: 42).

Aunque la premisa de acción continuaba sustentándose en la precariedad de las condiciones de vida de estas poblaciones, se incluyó como elemento innovador para la intervención el concepto de "capital social" 38 , para dar institucionalidad" a aquello que de alguna manera estuvo latente en la historia de los programas de desarrollo en la Sierra ecuatoriana: las formas de organización social de los "pueblos ancestrales", legitimadas esta vez, al menos desde la cooperación internacional, como “....agente potencialmente potenciador del desarrollo” (Bretón, 2001).

36 Guayaquil, Manta, Puerto Bolívar y Esmeraldas.

37 Impulsada en 1997 por el Banco Mundial, en convenio de crédito con el Estado ecuatoriano y el Fondo Internacional para el Desarrollo Agrícola (FIDA) (Cfr. Bretón, 2005).

38 Este concepto fue desarrollado por los teóricos del Banco Mundial. Putnam (1993) lo define como: “... la existencia de expectativas mutuas de cooperación entre los habitantes de una comunidad (o región) sostenidas por redes institucionales -las asociaciones u organizaciones- donde cristalizan en pautas de cooperación continuadas. Dicho con otras palabras: el capital social debe ser entendido como el conjunto de redes y normas de reciprocidad que garantizan la interacción y la cooperación social” (Bretón, 2001).

39 Fomentando la creación de Organizaciones de Segundo Grado como un agente representante de las organizaciones de base, asociaciones, comunidades, etc. 
Desde este enfoque, se inyectaron recursos directamente a las organizaciones de segundo grado $^{40}$, quienes eran finalmente las que mejor podrían gestionar los recursos asignados, siendo las más cercanas a los "requerimientos de su gente", además que la interlocución de éstas (Organizaciones de Segundo Grado-OSG) con otras instituciones gubernamentales (gobiernos seccionales) y no gubernamentales $\left[\mathrm{ONG}^{\prime} \mathrm{s}\right]$ ), se esperaba promoverían procesos de retroalimentación tanto de valores como de ventajas de gestión para su desarrollo (Cfr. Bretón, 2001).

En este contexto la problemática de la pobreza se reinterpretó también desde una plataforma política y desde la reivindicación étnica se la asumió como un reto a ser superado desde las propias iniciativas de la población con apoyo de las organizaciones indígenas (CODENPE) que comenzaban a gestarse como parte de la institucionalidad de un Estado pluriétnico y multicultural (Constitución del Ecuador, 1998).

El discurso desde la diferencia étnica, impregnó los proyectos de desarrollo sostenible y resaltaron todos los conocimientos ancestrales de la población indígena como un elemento enriquecedor de las propuestas puntuales de desarrollo local y conservación de la naturaleza.

Para el caso de la región Costa, el desarrollo rural también fue parte de la agenda nacional e internacional, sin embargo la lógica de intervención no dejó de partir de la ya sentada productividad agropecuaria de este territorio, siendo los proyectos de capacitación de la población campesina, por parte de técnicos especializados ${ }^{41}$, las estrategias de apoyo más comunes en la década de los 80, cuyo propósito se concentró en el mejoramiento de sistemas de cultivos y control de plagas que se encaminaron a recuperar (cacao) o mejorar productos agrícolas (banano) para la producción agroexportadora.

Para la década de los 90, PROLOCAL fue el alter de PRODEPINE para la población rural campesina mestiza (Crf. Bretón, 2005). Financiado por el Banco Mundial como parte de crédito reembolsable, este programa también pretendió reducir la pobreza en el país, apoyando los procesos de descentralización y gobernabilidad a través del desarrollo local (Guerrero, 2005). De este modo se buscó promover la formación y consolidación de organizaciones de segundo grado en la Costa con proyectos puntuales de desarrollo como sucedió en la área del humedal Abras de Mantequilla, donde las organizaciones de base pasaron a ser parte de la Federación de trabajadores agrícolas del cantón Vinces -FEDETACV, una organización de segundo grado que se formó en el marco del proyecto de riego para mejoramiento de cacao en la zona, patrocinado por PROLOCAL. A estos proyectos se anexaron componentes de conservación y actividades productivas alternativas; no obstante su racionalidad operativa mantuvo siempre la producción agropecuaria como el eje articulador de cualquier propuesta en provincias como la de Los Ríos $^{42}$.

Con esta probada fertilidad histórica de la provincia de Los Ríos, cuya estratégica ubicación geográfica la convierte además en un importante enclave comercial para el intercambio de los productos entre la Costa y la Sierra (Cfr. Naranjo, 2004), el tema de la pobreza manifestó una lectura distinta, ya que desde la racionalidad productiva es pobre solamente aquel que no tiene tierras; mientras un campesino posea tierras, su familia nunca va a pasar hambre.

40 De acuerdo a Bretón (2005), se estima que dentro de la nacionalidad Kichwa, 941 organizaciones de base recibieron apoyo de los recursos de PRODEPINE. Un total de 270.409 kichwas, es decir el $24 \%$ de la población total fue beneficiaria. En el caso de Imbabura, se apoyó a 14 organizaciones de segundo grado en 44 proyectos, convirtiéndose en la segunda provincia con mayores recursos invertidos de PRODEPINE.

41 Encomendados por organismos gubernamentales como el Ministerio de Agricultura y Ganadería

42 Para el censo del 2001, esta provincia registró el porcentaje más alto de población económicamente activa (PEA) dedicada a la agricultura, caza y pesca, con el 50.6\% (SIISE 4.5) de toda la región Costa, pasando a ser en el 2006 la provincia con la producción agropecuaria más alta de toda esta región, seguida de la provincia de Guayas y Manabí (Banco Central del Ecuador: Cuentas Provinciales 2001-2006 en: http://www.bce.fin.ec/frame. php?CNT=ARB0000974) 
Este principio básico para los campesinos montubios que viven alrededor de las Abras, es un elemento que además se complementa con el principio de abundancia que subyace en la percepción de éstos. La disponibilidad de recursos a los que pueden acceder los campesinos de manera gratuita, como el caso de pescado, el camarón, la fruta o el agua es algo que se ha normalizado y ha sesgado profundamente sus prácticas sociales sobre su entorno y su misma cotidianidad.

\section{El "éxito" de San Clemente}

A nuestro parecer, la actual propuesta de (eco) turismo en San Clemente es el resultado de varios procesos previos que la han retroalimentado hasta darle funcionalidad entre las propuestas relativamente exitosas de desarrollo sostenible. Estos procesos de manera directa o indirecta han estado vinculados con la lógica de intervención proyectivista que han modelado su actual dinámica.

\section{El turismo étnico y el valor agregado de "lo otavalo"}

El primer elemento relevante tiene que ver con el desarrollo turístico de la provincia de Imbabura en las últimas décadas. Este la ha posicionado como uno de los principales destinos turísticos del país. Actualmente, cuatro de los seis cantones ${ }^{43}$ han asumido el turismo como parte de la competencia de los gobiernos seccionales.

En gran medida el desarrollo del turismo en Imbabura ${ }^{44}$, tiene su origen en las manifestaciones étnico-culturales propias de los pueblos indígenas que aquí habitan y que ha favorecido más que nada a la consolidación de un turismo étnico. Sin embargo, las artesanías del grupo étnico de los Otavalo han sido las que han liderado y modelado el turismo en la provincia. Su tradición de artesanos-tejedores, registrada desde la época colonial cuando a éstos se les fue asignada la elaboración de prenda para la corona española (Kyle, 2001), los ha mantenido en la mira de ejemplos emblemáticos de desarrollo comercial.

A diferencia del resto de indígenas de la sierra, a los indígenas Otavalo se los ha representado históricamente como "especiales" y "limpios" (Íbid). Una característica que se fusionó con su vocación fabril y que en la época republicana más temprana fue una condición valorada dentro de la ideología del liberalismo, cuando Leonidas Pallares Arteta ${ }^{45}$ describirá al otavaleño como poseedor de habilidades deportivas y artísticas que se consideran potencialmente comercializables (Muratorio, 1994: 134).

Por otra parte, el hincapié que puso en su momento el proyecto de la Misión Andina en el "Proyecto Otavalo" 46 , “...teniendo en cuenta la aptitud especial de los trabajadores indígenas ecuatorianos en labores de artesanía” (Bretón, 2001: 66), también contribuyeron a fortalecer a través del tiempo un mercado étnico en donde "lo otavaleño" adquirió gran renombre y favoreció a consolidar lo que Kyle (2000) denominó como una "economía étnica transnacional".

En el presente, la producción de estos bienes culturales de los otavalo, dado su alcance internacional, no solo que han trascendido las redes familiares -consideradas en su momento la razón fundamental de su éxito (Ibíd)- sino que además han incorporado mano de obra de las comunidades aledañas, fomentando así su carácter artesanal. Sin embargo, la intensidad en la producción de éstos bienes culturales ha promovido redes de intermediarios que han precarizado

43 Otavalo, Ibarra, Cotacachi y Antonio Ante.

44 Ocupa el tercer lugar a nivel nacional con el porcentaje más alto $(10.5 \%)$ de población indígena (INEC).

45 Miembro de la Junta Directiva encargada de representar la cara del Ecuador en la celebración del cuarto centenario del descubrimiento de Colón, celebrado en Madrid en 1892 (Muratorio, 1994).

46 Basado en el mejoramiento de las técnicas de trabajo artesanal (Cfr. Bretón, 2001). 
la mano de obra femenina de dichas comunidades, que son las principales abastecedoras de los bordados a los centros de comercialización.

En el marco de turismo comunitario, la creación de una tienda de bordados en San Clemente ha sido una ventaja para las mujeres que la conforman, ya que, han dejado de vender sus prendas a costos extremadamente bajos (hasta sesenta centavos de dólar ${ }^{47}$ ), pudiendo ahora ofertar sus bordados a los consumidores finales (obteniendo hasta 100 dólares por prenda ${ }^{48}$ ). Sin embargo, hay que anotar también que la persistencia de esta habilidad étnica de las mujeres, en comunidades como San Clemente, La Esperanza, Zuleta, Angochagua -mantenida en gran medida por estas redes de producción y comercialización- ha pasado a ser el centro de programas de turismo étnico a nivel cantonal, como por ejemplo el que auspicia el Municipio de Ibarra a través de la "ruta de los bordados", en donde el bordado artesanal de las mujeres se la asocia con la manifestación cultural del entorno geográfico y natural del cantón.

En definitiva, los bordados son el producto cultural por antonomasia que representan las artesanías en San Clemente, éstos son el "producto cultural" visible del turismo étnico y emblemático hacia afuera dada su relación directa con "lo otavalo" como la "marca registrada" en el mercado artesanal.

\title{
El movimiento indígena y el discurso de la conservación
}

La injerencia del movimiento indígena que para principios de los 90, como menciona Bretón (2002: 44) “...logró condensar en la CONAIE, la que probablemente haya sido hasta el momento la plataforma de reivindicación identitaria con mayor capacidad de movilización y de interpelación de América Latina", causó un profundo quiebre en el auto reconocimiento de la población indígena no solo como grupo étnico, sino también como sujetos individuales que cuestionaron de la manera más cotidiana su existencia; construida desde un orden social establecido a través de la educación, la religión, los sistemas de salud formal, etc., como a continuación podemos apreciar en el siguiente testimonio:

\begin{abstract}
"Una cosa es estar viviendo en la comunidad, en la familia pero cuando uno sale afuera cambia todo por eso digo a veces la educación en vez de fortalecer nos viene a desvalorizar nuestro identidad. Yo estuve a punto de perder mi identidad, en el colegio estuvimos alumnos de Ibarra, en ese sentido la educación confunde la realidad de una comunidad, está direccionada a un tema de interés de un grupo no te educan para valorar lo que uno tiene alrededor, es una imposición, en ese sentido, en el colegio con los amigos yo no era indígena, yo era otro mestizo, por eso yo recuerdo una vez cuando yo caminaba con mis compañeros me encontró mi papá con lo que se pone hasta ahora las alpargatas y el poncho y yo me escondí de mi papá para decir que no es mi papá pero ahora yo digo no porque el valor que tiene una cultura que se tienen muchas cosas empezando desde el idioma y me involucro en una cultura donde a veces ni ese idioma sabemos hablar bien entonces ese sistema es ilógico y eso pasa por culpa de la educación porque no nos hacen ver la importancia de las culturas que existen el Ecuador hasta este momento" (Entrevista J.G, 2007).
\end{abstract}

La institucionalización de entidades indígenas dentro del Estado fue quizás el logro más representativo de esta lucha reivindicativa, que favoreció a la participación creciente de personajes indígenas en los gobiernos seccionales, sobre todo en las provincias con un elevado porcentaje de población indígena como Imbabura ${ }^{49}$. Esto ha contribuido en gran medida a poner sobre la

47 Estas prendas por lo general son piezas separas que se utilizan para armar blusas, chales, manteles, etc., para ser comercializadas en la ciudad de Otavalo.

48 Dependiendo de la complejidad de la prenda (caminos de mesa, camisetas, mantelería, blusas) y del tiempo de elaboración.

49 Esta provincia ocupa el tercer lugar a nivel nacional con el porcentaje más alto de población indígena (10.5\%), después de Chimborazo con el 18.5\%, seguido de la provincia de Pichincha con el 11.5\% (INEC, 2006). 
agenda temas considerados como prioritarios dentro del marco de reivindicación y revalorización étnica en los planes de desarrollo local (provincial, cantonal, parroquial). El turismo en este sentido, ha sido un buen catalizador de estas prioridades que le han provisto de una plataforma política y económica a prácticas sociales, formas de vestir, idioma, cosmovisiones, manejo de territorio, traducido todo esto en "productos culturales".

Sin embargo, la vinculación del desarrollo con la sostenibilidad de los territorios ha sido un eje axiomático que ha complementado la reivindicación étnica, pues en un país tan biodiverso como el Ecuador el tema de la conservación se relacionó estrechamente con un discurso antiimperialista que acusaba al sistema de producción capitalista como responsable de haber trastocado profundamente las formas tradicionales de uso de la naturaleza (conocimiento ancestral).

Con esta premisa, se enunciaba tácitamente que las comunidades indígenas siempre habían estado cercanas a la naturaleza, de ahí la existencia de sus prácticas ancestrales; por lo tanto la reivindicación étnica también pasó a ser un tema de preservación. Como una relación complementaria, armónica y hasta inseparable en algunos casos (indígenas que habitan en la amazonia), se llegó a considerar la relación entre la naturaleza y los pueblos indígenas, que desde el punto de vista de la revalorización cultural comparten el mismo riesgo de extinción.

Por lo tanto, en este marco reivindicativo, la propuesta turística de San Clemente, no necesita contar con un territorio completamente rural con un alto grado de sensibilidad ecológica para ser parte de las propuestas de desarrollo y conservación sostenible. En definitiva, con esta condición sine qua non de su "filosofía de entendimiento de la naturaleza", su propuesta se integra con otras condiciones dadas que hacen parte de su ubicación territorial y que en términos operativos son una ventaja, como el hecho de estar cerca al casco urbano, lo que facilita a los turistas su acceso a la infraestructura urbana (transporte, servicios de hoteles, centros nocturnos, etc.), al mismo tiempo que pueden vivir un experiencia vivencial con el "buen salvaje".

\section{El sentido micro-empresarial del turismo comunitario}

La actual organización del turismo comunitario le ha dado un sentido de organización territorial mixta a San Clemente, ya que, en la práctica, además del Cabildo como la entidad rectora de la cohesión comunitaria, se ha creado una directiva específica a parte con las familias que son parte propuesta turística y si bien no existe conflicto entre estas dos instancias a nivel formal, hay un latente malestar entre algunos de los habitantes que no son parte directa del turismo vivencial.

Quizás éste sea un de los puntos donde se identifica mayor conflicto social en relación al turismo; pues no solo se han comenzado a dar diferencias sociales entorno al tema arquitectónico (construcción de las cabañas) sino que además se percibe la instrumentalización del Cabildo para realizar trabajos que convocan a toda la comunidad a través de la minga pero que finalmente solo benefician a las familias que reciben turistas. Sin embargo, este antagonismo está menguado por un discurso de sostenibilidad territorial que resalta el riesgo de saturar el espacio comunitario si todo el mundo recibiera visitantes; por lo que se ha previsto como una alternativa la generación de redes comerciales basadas en la vecindad (dentro de la misma comunidad o con otras comunidades) que abastezcan ya sea con productos (leche, carne) o servicios (bicicletas, guías, caballos) a las familias que reciben turistas.

Por otro lado, la administración de las cabañas de hospedaje por determinadas familias en la comunidad refleja una lógica micro-empresarial ${ }^{50}$, cuya característica más importante ha sido el reconocimiento del hombre y de la mujer como sujetos de crédito. Esto en gran medida fue

50 Esto fue parte componencial de los programas de desarrollo de finales de la década de los 90, cuando se motivó la creación de entidades locales prestamistas (cajas solidarias, cooperativas, fondos comunes) que proveyeran de "capital semilla" a proyectos familiares agrícolas. 
motivado por la migración estacional de población masculina que llevó a las mujeres a liderar los procesos de capacitación y empoderamiento de programas específicos de desarrollo y que en la presente coyuntura del turismo ha permitido que ambos puedan acceder a microcréditos encaminados a la construcción de las cabañas de hospedaje o para la inversión en materia prima para la elaboración de bordados.

Otro hecho distintivo que se puede apreciar en el turismo comunitario de San Clemente, es la inclusión del espacio doméstico, tradicionalmente manejado por las mujeres, dentro de una racionalidad económica formal, esta particularidad ha permitido que la mujer obtenga mayor control sobre los ingresos económicos propios del hospedaje, alimentación, cursos de kichwa o bordado, venta de bordados, etc.; que ha motivado la participación de los hombres en esta dimensión, tradicionalmente relegada a las estrategias de subsistencia.

\section{EI "fracaso" de El Recuerdo}

Desde el punto de vista técnico de las personas que trabajaron directamente con el proyecto y le han podido dar seguimiento, consideran que no tuvo los resultados que se esperaba y que más bien estos han sido pocos e incipientes para la conservación de este ecosistema. Así por ejemplo, lo único que queda del componente agroecológico es la planta de biol que actualmente se utiliza para criadero de gallinas; se ha descontinuado el cultivo de los huertos agroecológicos y finalmente, todos los árboles sembrados en los bordes del humedal han desparecido a causa de las prácticas de quema pos cosechas realizadas por los campesinos. Por otro lado, la cabaña ecológica construida frente al malecón del humedal todavía no se ha habilitado para recibir turistas; mientras que, las personas que recibieron capacitación como guías locales no ejercen sus funciones como tal y aún no han obtenido sus certificaciones abaladas el Ministerio del Ambiente.

En términos generales, éstas son razones suficientes para que los técnicos atribuyan la responsabilidad del virtual fracaso del proyecto a la falta de compromiso de sus habitantes y en el caso específico del turismo en El Recuerdo a la falta de liderazgo y empoderamiento de sus dirigentes; pero además a la imperante desorganización social -dicen éstos- que ha dificultado los procesos de gestión para el cuidado del humedal. Sin embargo, el argumento dominante entre los técnicos tanto de FUNDAR como de la ASEC hace alusión al paternalismo, como un estado normalizado entre la población que está "acostumbra siempre a recibir" (entrevista, C.T., 2007), ya sea por parte de las instituciones estatales o de la naturaleza.

La disposición y fácil acceso de las poblaciones como El Recuerdo a los recursos naturales del humedal, se ha esgrimido como fuerte argumento para legitimar la deficiente partición de las personas. Esta "maldición" de la abundancia se ha considerado como un arma de doble filo, que si bien por una parte detiene (por ahora) los procesos migratorios -característicos de poblaciones que no cuenta con sistemas locales de sustento y se ven en la necesidad de salir a centros mejor abastecidos-; por otro lado, impide la valoración de propuestas que prevengan o mitiguen la escasez y el eminente colapso de las fuentes de sustento.

\section{Producción agropecuaria vs. Conservación}

Los Ríos es la única provincia de la región Costa que no tiene salida al mar, una condición geográfica que al parecer no le ha hecho falta, dado que su territorio de $7.175 \mathrm{Km} 2$ se ha dedicado exclusivamente a la actividad agropecuaria, al punto de que dentro del Sistema Nacional de Áreas Protegidas del Ecuador (SNAP) no hay una área que esté dentro de esta provincia.

En tal sentido, la intencionalidad de técnicos locales por modificar las prácticas "poco 
sustentables" con el medio ambiente en esta provincia, se encuentra con un entramado de prácticas productivas que no solo obedecen a una racionalidad económica, sino que además alrededor de éstas confluyen formas de conquista y transformación de la naturaleza.

Como la prueba más palpable de esta racionalidad, el humedal Abras de Mantequilla se encuentra totalmente parcelizado, consecuencia del permanente esfuerzo de los campesinos que lo han conquistado primero y lo han transformado luego en un lugar más productivo; y a pesar del recuerdo aún latente en la memoria colectiva de sus pobladores, cuando aluden a los frondosos árboles frutales y la gran variedad de flora y fauna que alguna vez cubrió el humedal, su fertilidad está medida en última instancia por la capacidad de mantenerse en el tiempo, a pesar de todas las transformaciones relativamente rápidas que tuvo el humedal en la primera mitad del siglo XX, con los procesos de producción agropecuaria.

Desde esta perspectiva, la tierra constituye el elemento articulador a partir del cual el resto de recursos naturales se han ido priorizando para los habitantes del humedal, pues ésta además de ser el medio de producción de los agricultores campesinos, es el espacio de vida donde confluye su cotidianidad. Es el espacio domesticado; mientras que el agua es un recurso todavía no del todo controlado desde la racionalidad productiva, haciendo que la relación de este recurso con la población esté mediada tradicionalmente por el recelo y la incertidumbre (a causa de las inundaciones). No obstante, desde el enfoque de la declaratoria RAMSAR el agua es la razón más importante del humedal, dada su alta concentración en determinada época del año que contribuye a procesos ecológicos lo suficientemente complejos y sensibles para incluir a las Abras en la lista de humedales de importancia internacional.

Esta conceptualización científica de las Abras, es precisamente la contraparte de la racionalidad productiva del humedal, que se introdujo a través del proyecto FUNDAR-PPD mediante el componente educativo y de talleres. La preocupación sobre todo por las especies faunísticas que habitan en ella (lobos marinos, nutrias, peces, etc.) o dependen de ella (aves migratorias), fue la temática central de concienciación en el componente de educación ambiental y valoración turística, y donde los técnicos pusieron mayor énfasis para difundir el discurso de conservación.

\section{FUNDAR... del crédito agropecuario a ¿la conservación?}

Si bien, la dilatada experiencia de trabajo de FUNDAR como entidad crediticia en la zona, favoreció en gran medida para que sus técnicos puedan ejecutar el proyecto con buena aceptación de la población, consideramos que al menos dos elementos ameritan mencionarse como condicionantes previos.

En primer lugar, su gestión directa con las organizaciones de base demostraron en la práctica del proyecto la legitimidad que FUNDAR tiene en la zona, a diferencia del proyecto de PROLOCAL que en el 2001 no contó con suficiente aceptación y que en su ejecución presentó muchas dificultades que se vieron reflejadas en la gestión de la FEDETACV.

La organización en recintos como el Recuerdo, dependen sobremanera de las relaciones familiares, vecinales, simbólicos, espaciales, mediante las cuales se establecen las negociaciones con las directivas o asociaciones que tenga algún tipo de representatividad hacia afuera. Esta lógica no fue tomada en cuenta por los técnicos de PROLOCAL, quienes asumieron que la conformación de la FEDETACV como un organismo de segundo grado que representara a las organizaciones de base de las Abras era suficiente para promover la participación y desarrollo local. FUNDAR, por su parte tuvo y tiene la ventaja de que su director sea oriundo de las Abras y propietario de tierras en El Recuerdo, favoreciendo a que esta entidad sea parte del entramado social.

Asimismo, un segundo factor previo a considerar, tiene que ver con el manejo de los recursos económico en el marco de la racionalidad campesina. El dinero corriente no es parte común de las relaciones de producción, por lo general todo entre los campesinos se encuentra invertido, lo que 
quiere decir que las transacciones se realizan casi siempre en bienes (tierra, ganado) o productos (arroz, maíz, mano de obra). Así por ejemplo, la buena administración del gobierno seccional se encuentra medida por las obras visibles realizadas, como el caso del pequeño malecón construido y la gabarra donada en el recinto El Recuerdo, son indicadores de una alcaldía "exitosa".

Los recursos económicos entregados por PROLOCAL a dirigentes de la FEDETACV para la compra de bombas de agua para el riego del cacao generó polémica, pues siendo poco común el manejo de dinero corriente -sobre todo si se trata de sumas considerables-, el cuestionamiento directo a esta organización desencadenó mucha desconfianza entre los miembros que terminaron por desvincularse de la organización; y aunque la FEDETACV todavía existe como OSG en la zona, su intervención y presencia como representante de las organizaciones de base de las Abras, terminó junto con el proyecto de PROLOCAL. En cambio, en el marco del proyecto FUNDARPPD, el dinero fue administrado en su totalidad por FUNDAR, siendo medibles sus beneficios en obras concretas como la construcción de la cabaña turística y la planta de biol en el recinto El Recuerdo, que finalmente se ajustaron a una lógica paternalista.

\section{La conservación. Un discurso de poder en las Abras}

El discurso biologizante sobre el que se justificó la conservación de las Abras, puso de entrada a los técnicos en una posición de superioridad dada la especialización técnica de la información. Los técnicos amparados bajo el capital social de FUNDAR, pudieron ser parte de una dinámica basada en la confianza y la familiaridad que además estuvo condicionada por la prolongada permanencia de éstos en el recinto El Recuerdo, que fue la base operativa del proyecto, al punto que la coordinadora del proyecto -oriunda de Guayaquil- pasó a ser parte de la directiva del recinto ocupando el cargo de secretaria, lo que la envistió de autoridad para liderar y tomar decisiones relacionadas no solo con el proyecto sino con la misma organización social del Recuerdo.

Con el término del proyecto FUNDAR-PPD, este tipo de entramado social ad hoc se deshizo, sin embargo FUNDAR no dejó de coordina actividades relacionadas con la conservación del humedal, convirtiéndose en la entidad con mayor legitimidad en las Abras para tratar esta problemática desde una posición de autoridad, que no solo le ha permitido censurar las prácticas "poco amigables" con el ambiente; sino también, para liderar y ejecutar acciones concretas de conservación que a su parecer son convenientes para el humedal, como a continuación se puede apreciar en el siguiente testimonio:

\footnotetext{
"Hay algunos niños por ahí que están medio descarriaditos...[menciona un nombre] él tiene el asunto de coger animales y tenerlos en jaula tanto fue así que hace algunos meses tenía un tigrillo, y ese es el tercer animal que se le muere. Primero nosotros introducimos un mono que lo compramos aquí, cosa con la que no estaba de acuerdo, pero mi jefe me dijo cómprelo para que lo introduzca en Abra, pero en el momento en que se lo introdujo este señor lo capturó y lo hizo de su propiedad. Yo no quise entrar mucho en eso. El tipo lo agarro, pero el monito no le duró, entonces ese fue el primer animal. Según comentan que el perro lo mató. Otros dicen que lo vendió, después por un pajón encontró una nutria, la capturó. La nutria es animal que si puede está en cautiverio por los estudios que se han hecho, pero como yo soy bien conservacionista no me gustan ver animales en jaula, lo tubo en jaula un tiempo, el animalito a veces le comía otras veces no. Lo bueno, que el tiene es que el tiene niñas entonces con la niñita se pegaba muy bien pero parece que alguien lo ojeo subió una temperatura fuerte el animalito y también se le murió" (Entrevista C.T., 2007).
}

Como se puede ver en este fragmento de testimonio de la coordinadora del proyecto y técnica de FUNDAR, el tema de conservación parte de una acción concreta de uno de los habitantes del Recuerdo, como lo más emblemático de "prácticas no conservacionistas" en el humedal, es decir, el intento de domesticación de especies agrestes, que finalmente representan todo lo no conquistado y asimilado dentro de la racionalidad productiva de la población. 
Por lo tanto, si bien FUNDAR introdujo el discurso de la conservación como un tema aparentemente antagónico con las prácticas productivas en las Abras, en la misma ejecución del proyecto las estructuras productivas no fueron motivo de cuestionamiento, sino que se creó un discurso paralelo a partir de aquellos recursos que no son parte de estas estructuras (agua, mamíferos acuáticos y terrestres, aves), permitiendo mantener la legitimidad de FUNDAR como una entidad vinculada con y sobre todo la racionalidad productiva de las Abras, pero adicionalmente obtuvo autoridad de palabra y de acción sobre lo que es "bueno" o "malo" para la conservación de este humedal.

\section{De la abundancia a la distribución de uso de los recursos naturales....un problema sin resolver.}

Si bien es cierto, que la abundancia de los recursos naturales es una condición remarcable en las Abras, creemos que este tema ha sido tratado desde una visión muy superficial por parte de los técnicos, cuya mayor motivación se ha basado más que nada en la declaración de este humedal como sitio RAMSAR, dejando de lado otras razones que han marcado de manera profunda las actuales condiciones ecológicas de las Abras.

El tema de la distribución de tierras en toda la provincia ha dado lugar a una profunda diferencia socioeconómica entre la población. Esto no es ajeno a la zona de las Abras, donde a pesar de que las tierras distribuidas originalmente vía herencia fueron de extensiones considerables, en la actualidad la redistribución a los descendientes de los campesinos originarios ha llevado a una exacerbada minifundización de las mismas, que termina siendo más que nada espacios de vivienda antes que tierras de producción agrícola.

Con este trasfondo, hay que agregar el hecho de que por lo general los hacendados constituyen la representación política y social más importante frente a las autoridades locales en Vinces, dada su capacidad productiva y su ostentación sobre los medios de producción (tierra, tecnología, mano de obra, etc.). Por lo tanto, el uso de los recursos naturales también se encuentra marcado por estas diferencias estructurales. En el caso de las Abras, se presenta un claro ejemplo de esto, cuando en el 2003 una hacienda bananera ubicada aproximadamente a dos kilómetros aguas debajo del recinto El Recuerdo, abrió un canal, de alrededor 500 metros, desde el área inundable del humedal hacia sus tierras de cultivo con el fin de obtener agua de riego para sus plantaciones. Esto ha provocado la disminución del caudal, sobre todo aguas abajo después de la hacienda, lo que trae como consecuencia el estancamiento de las aguas y la acumulación de "lechugas ${ }^{51}$ ".

Por lo tanto, los problemas ecológicos de las Abras, se miden desde el discurso internacional de conservación que termina de ser una visión fragmentada de la realidad, que en este caso exime de responsabilidad a ciertos actores locales; mientras que responsabiliza por completo a otros cuya "condición de pobreza" los acusa de ser los causantes del deterioro de este ecosistema.

\section{El (eco) turismo... ¿Una solución para las Abras?}

Dentro del componente de (eco) turismo, se podría decir que los parámetros sobre los cuáles éste se erigió, también respondieron a valores internacionales de lo que debería ser el "turismo de naturaleza" y a pesar de que la presencia de la ASEC y los talleres liderados por estos para motivar la actividad, tomando como referente otras experiencias en el país de alguna manera le dieron cierto contexto al turismo en las Abras, esto no significó necesariamente la consideración de aquellos elementos sociales y culturales locales que bien pudieran ser recuperados tanto para la conservación como para el turismo en la zona.

51 Es una especie de planta acuática que en grandes cantidades dificulta el paso de canoas y concentra sedimentos. 
Así tenemos, entre los más importantes que se pudieron identificar durante la investigación: el tema de las regatas campesinas, las tradicionales técnicas de pesca, la elaboración de canoas y la tradición oral mítica alrededor del humedal. Todas estas nos hablan de la interacción de las personas con el entorno, que si bien son colonos no son poblaciones completamente ajenas a los sistemas lenticos, dado que en su mayoría son originarios de cantones cercanos con sistemas ecológicos parecidos.

Así por ejemplo, las técnicas de pesca tradicionales, que ahora están perdiéndose frente a otras más modernas y de mayor uso entre los pescadores de la zona, han sido parte de "conocimientos antiguos" asociados con ciclos de pesca, ciclos de reproducción de las especies, ciclos climáticos que se asociaron alguna vez con el aparecimiento de cierta fauna (aves migratorias, lobos de agua) y se utilizaron como indicadores para la práctica exitosa de la pesca artesanal.

El uso de las canoas a remo, son también una muestra de la tecnología asociada con el medio ambiente, pues este tipo de transporte, tradicionalmente elaborado a mano con madera de árboles de la zona se ha utilizado tanto como transporte de personas como para las actividades de pesca. Sin embargo, en las últimas décadas se ha comenzado a reemplazar los botes a remo por las canoas de fibra de vidrio y a motor, algo que se ha evidenciado en las regatas campesinas.

Las regatas campesinas son la manifestación sociocultural que expresa las vinculaciones de la gente con las aguas del humedal. Sus ciclos de inundación, se explican a través de una racionalidad religiosa de origen cristiano-católico. Pues los cultivos de arroz se organizan en función de las tres crecientes que llegan al humedal: la de San José (Diciembre); la de Domingo de Ramos (Abril) y la de las Cruces (1 de mayo), las cuales predicen los beneficios o maleficios del año invernal.

El agua, en última instancia es el recurso natural con el que menos relación productiva tiene la gente, pero por otro lado, el respeto y temor que ésta infunde desde las más pasadas historias (cuando se recuerda al humedal repleto de lagartos), ha dado pie para construir a través de la tradición oral una serie de mitos que reflejan finalmente las formas de organización social que se encuentran fuertemente arraigas entre lo que sería lo femenino y lo masculino en la cosmovisión campesina montubia.

Todos estos elementos que no han sido tomados en cuenta durante el proyecto FUDNAR-PPD, bien podrían ser reconsiderados no necesariamente para armar una propuesta turística, sino para reavivar prácticas de la misma población que "recuerden" los vínculos con este espacio lentico. Quizás el turismo en las Abras no sea lo más idóneo, pues tomando en cuenta la configuración espacial de esta zona (parcelizada), y la completa ausencia de una política de planificación territorial por parte de los gobiernos seccionales, el humedal corre un alto riesgo de privatizarse pues en la actual situación de los campesinos, éstos son propensos a vender sus tierras por "atractivas" ofertas ya sea por parte de hacendados vecinos o de empresarios interesados en construir complejos turísticos.

\section{Conclusiones}

Con la legitimización de la ciencia positiva como paradigma de progreso humano de las sociedades modernas, lo que se ha denominado como naturaleza, se ha interpretado desde una relación de poder, donde ha pasado de ser de un objeto de explotación humana -consecuencia del desarrollo económico tradicional- a un sujeto frágil, necesitado de cuidado (con el discurso del desarrollo sostenible). En todo caso, desde las dos perspectivas prevalece la capacidad del ser humano por destruirla o protegerla.

El desarrollo sostenible más que un "nuevo" paradigma, es una estrategia operacional que 
pretende establecer límites al usufructo de la naturaleza en el marco del desarrollo económico mundial. Sin embargo, desde la dicotomía entre los países desarrollados y subdesarrollados este discurso profundiza sus diferencias y las esencializa como características perennes, sin tomar en cuenta los procesos históricos que las originaron.

Latinoamérica, es un gran laboratorio para la implementación de las propuestas de "turismo responsable" a pequeña escala, no solo por sus condiciones ecológicas y la presencia de culturas con "distintas racionalidades" en su interacción con la naturaleza, -dos condiciones alineadas con el estereotipo de conservación y desarrollo del turismo mundial sostenible-; sino porque la institucionalidad ambiental consolidada a partir de la década de los 90, promovió el involucramiento de una multiplicidad de actores (Estados, Ong, movimientos sociales, comunidades, personas, empresas, etc.), que respondieron ante todo a los requerimientos de la agenda internacional, que en gran medida -gracias al flujo de los recursos económicos de la cooperación internacional- instrumentalizó el discurso de la conservación y lo tradujo en términos de beneficios económicos a través de lo (eco) turístico.

En el caso específico del Ecuador, su acoplamiento con los valores universales del desarrollo sostenible han sido anacrónicos. Han respondido más que nada a eventos coyunturales (conferencias y convenios internacionales), y políticas internacionales antes que a iniciativas estructuradas desde sus propios contextos (históricos, sociales, culturales, ecológicos). Por lo tanto, las propuestas (eco) turísticas también se ajustan dentro de este marco de gestión, que ha tenido que ver más que nada con una lógica privada de corte micro-empresarial, secundada por el mismo Ministerio de Turismo, cuyo trabajo se ha constreñido a su rol como agente publicitario de los "productos turísticos" del país, antes que a un entidad coordinadora y agenciadora de políticas públicas de largo alcance.

El (eco) turismo como una empresa sostenible de desarrollo económico para los países subdesarrollados, se vislumbra en el presente como el mayor mérito de la industria turística que ha previsto en la conservación de la naturaleza su fuente de beneficio económico. Sin embargo valdría la pena preguntarse, cuál es el real beneficio de este turismo "alternativo" en los programas de conservación de las áreas ecológica y socioculturalmente sensibles localizados en estos países, tomando en cuenta que el turismo en su real magnitud (como en el caso de Galápagos) no ha dejado de desprenderse de aquellos requerimientos técnicos, económicos de inversión, de servicios (transporte, logística, promoción, consumo, etc.), que hacen precisamente se mantenga como un importante sector económico para los países desarrollados. Desde esta perspectiva nos preguntamos qué tan sostenible económicamente hablando es el turismo para las poblaciones o comunidades que se encuentran ajenas a esta lógica (como El Recuerdo), y cuya "capacitación" se remite a un tiempo determinado, definido en la ejecución de un proyecto específico; y en el caso de que todo este conocimiento pueda ser "asimilado" por la población objeto, y el turismo pueda despegar (como en San Clemente), territorialmente hablando que tan sostenible éste puede mantenerse en el tiempo si logra encadenarse a los circuitos turísticos mundiales.

El turismo comunitario de San Clemente se encuentra permeado por la herencia proyectivista de los programas de desarrollo que se implementaron en la Sierra centro-norte desde la década de los 50. Y si bien bajo el paradigma del "desarrollo de la comunidad" se esperaba re-funcionalizar las estructuras sociales de organización de las comunidades indígenas como un medio para promover el desarrollo agropecuario del sector rural; bajo el marco de desarrollo sostenible, las poblaciones indígenas como tal se convierten en el objeto en sí mismo de desarrollo económico a través de la propuesta (eco)turística; siendo el más claro efecto de esto la inclusión de la esfera doméstica indígena dentro de la lógica de mercado traducida en "turismo vivencial".

El valor agregado de "lo otavalo" en la provincia de Imbabura, no solo hace referencia a las artesanías que han dado renombre a esta etnia y al país a través de ella, -gracias a los circuitos de comercialización que han trascendido el mercado nacional-, sino también por su construcción social a través del tiempo como un estereotipo étnico de progreso económico. Esto promueve un alto riesgo de homogenización cultural en la provincia de Imbabura, siendo las diferencias 
étnico-culturales suprimidas en beneficio de un turismo étnico institucionalizado a través de la promoción de los gobiernos seccionales y de las mismas comunidades, quienes encuentran cada vez más viable reproducir "productos culturales" como los bordados para obtener beneficios económicos.

Si bien, en la década de los 90, la reivindicación étnica caló profundamente la estructura excluyente del Estado ecuatoriano y la irrupción política del movimiento indígena causó un quiebre definitivo en las formas de participación política ciudadana; el discurso del desarrollo sostenible menguó este proceso a través del discurso de la conservación que desvió el tema de la reivindicación étnica hacia una esfera internacional, cuya principal consecuencia ha sido la ambigüedad de sus contenidos vaciados por principios hegemónicos que han esencializado el tema étnico en términos de exotización y arraigo a una "estado de naturaleza" bajo el discurso de la conservación y el (eco) turismo.

La provincia de Los Ríos, responde a una racionalidad productiva que tradicionalmente ha sido fomentada por el Estado, apenas se han hecho ajustes que en muy poco han variado las formas de apropiación y uso de los espacios para las actividades agropecuarias. Por lo tanto, las estructuras organizativas a todo nivel se han dispuesto de esta manera, en donde desde los campesinos hasta las instancias gubernamentales o no gubernamentales convergen bajo una lógica de colonización y apropiación de los recursos naturales con propósitos productivos.

El proyecto FUNDAR-PPD respondió a una coyuntura específica que tuvo que ver con la declaratoria del Humedal Abras de Mantequilla como sitio RAMSAR en el 2000. Por lo tanto, el proyecto como tal fue una intervención externa y unilateral que tuvo apertura no precisamente por la propuesta sino por quienes ejecutaron la propuesta, y en este sentido, la conservación del humedal se tradujo en términos de un discurso especializado -a través de los talleres de capacitación sobre la biodiversidad-, que contribuyó a fortalecer la autoridad de FUNDAR, que además de su previa legitimidad en la esfera productiva pasó a convertirse en un agente protagónico en las acciones de conservación de Las Abras bajo criterios de discrecionalidad.

Las propuestas de conservación y turismo en las Abras, son parte de un discurso hegemónico que ha sustentado su razón de ser en categorías estereotípicas de pobreza y de naturaleza en los países subdesarrollados. Desde parámetros objetivizados (poblaciones, prácticas sociales, formas de ver lo natural, conservación) por la lógica de intervención, el real aporte que pudo dar el proyecto FUNDAR-PPD a las Abras de Mantequilla y a sus poblaciones, difícilmente consideraron la complejidad sociopolítica de este territorio, cuyo articulado social se enmarca en dinámicas de poder, donde no son exclusivamente los "pobres" los que deprendan los recursos; y la conservación del humedal no necesariamente puede conseguirse a través de alternativas económicas como el (eco) turismo.

\section{Bibliografía}

Asociación Ecuatoriana de Ecoturismo, s/f, Reglamento de Ecoturismo, Quito.

Azevedo Luíndia, Luiza. 2007, Ecoturismo Indígena, Abya-Yala, Quito.

Azócar de Buglass, Leida, 1995, “Ecoturismo, ¿una alternativa de desarrollo sostenible?”, en: Ecoturismo en el Ecuador. Trayectorias y desafíos, UICN, Quito, pp. 9-53.

Banco Central del Ecuador. Cuentas Provinciales 2001-2006 en: http://www.bce.fin.ec/frame. php?CNT=ARB0000974

Bretón, Victor, 2005, “Glocalidad y reforma agraria: ¿de nuevo el problema irresuelto de la tierra?”, en: Íconos 
24. Revista de Ciencias Sociales, FLACSO-Ecuador, FLACSO, Quito, enero 2006.

Capital social y etnodesarrollo en los Andes, CAAP, Quito.

Cooperación al desarrollo y demandas étnicas en los Andes ecuatorianos, FLACSO-Universidad de Lleida, Quito, 2001.

Calderón, Francisco José, 2005, Distrito turístico rural un modelo teórico desde la perspectiva de la oferta. especial eferencia al caso andaluz, tesis doctoral, Málaga.

Cañada, Ernest y Jordi Gascón, 2007, Turismo y desarrollo: herramientas para una mirada crítica, 1a. edición, Managua, Enlace.

Canzanelli, Giancarlo, 2004,"Valorización del potencial endógeno, competitividad territorial y lucha contra la pobreza", Center for International and Regional Cooperation for Local Economies, en: http://www.redelaldia. org/IMG/pdf/948.pdf .

CEPAL, 2006 Panorama social de América Latina, en: http://www.eclac.cl/publicaciones/xml/0/27480/PSE2006 Sintesis_Lanzamiento.pdf

Cepal, Pnuma, 2002, La sostenibilidad del desarrollo en América Latina y el Caribe: desafíos y oportunidades, Chile.

CEPAL, PNUD y PNUMA, 2001, El financiamiento para el desarrollo sostenible en américa latina y el Caribe, Conferencia Regional de América Latina y el Caribe preparatoria de la Cumbre Mundial sobre el Desarrollo Sostenible (Johannesburgo, Sudáfrica, 2002), en: http://www.eclac.org/publicaciones/xml/9/8239/lcg2146e. pdf

Cordero Ulate, Allen, 2006, Nueves ejes de acumulación y naturaleza. El caso del turismo, CLACSO, Buenos Aires.

CASTELLS, Manuel. La era de la información: economía, sociedad y cultura. Madrid: Alianza, segunda edición 2000-2003.

Escobar Arturo, 2005, “El post desarrollo como concepto y práctica social” en: http://www.globalcult.org.ve/pub/ rocky/libro3/escobar.pdf.

2000, “El lugar de la naturaleza y la naturaleza del lugar: ¿Globalización o Posdesarrollo?”, en: www.clacso.org/ wwwclacso/espanol/html/libros/lander/6.pdf,

1998, "la problematización de la pobreza: la fábula de los tres mundos y el desarrollo", en: La Invención del Tercer Mundo. Construcciones y deconstrucciones del desarrollo, Norma, Bogotá.

Diaz-Polanco, Hector, 1989, Las teorías antropológicas, la Evolución, Juan Pablo editor, Mexico.

FUNDAR-PNUD. Proyecto apoyo comunitario a la conservación del humedal Abras de Mantequilla en el cantón Vinces, provincia de Los Ríos 2002-2004.

Guerrero, Fernando "Desarrollo local en tiempos de globalización: los desafíos del PROLOCAL en las microregiones del Sur de Manabí y la Cuenca Alta del Río Jubones", Ponencia Presentada en el Primer Encuentro Ecuatoriano de Investigación sobre la Sociedad Rural. FLACSO - ALASRU Quito del 26 al 27 de octubre de 2005, C.PUCE- Escuela de Sociología y Ciencias Políticas, Quito.

Gudynas, Eduardo, 2003, Ecología, economía y ética del desarrollo sostenible, Abya-Yala, Quito.

Habermas, Jürgen, 1999, Ciencia y técnica como ideología, Tecnos, Madrid.

Hidalgo, Fernando, 2007, Descripción de fuentes históricas de los antiguos bosques del Ecuador, Banco Central del Ecuador.

Muñoz de Escalona, Francisco. El turismo explicado con claridad, 2007, Edición electrónica gratuita, en: www. eumed.net/libros/2007c/310/

Naciones Unidas, 1946, "Primera sesión Plenaria", jueves 10 de enero de 1946, en: http://www.un.org/depts/dhl/ landmark/pdf/a-pv1s.pdf .

Kyle, David, 2001, "La diáspora del comercio otavaleño: capital social y empresa transnacional", en: Ecuador Debate $\mathrm{N}^{\circ}$ 54, CAAP, Quito, pp. 85-110.

Larrea, Carlos. Hacia una historia ecológica del Ecuador, Universidad Andina, Corporación Editorial Nacional, EcoCiencia, Ecuador, 2006.

Leff, Enrique, 2000, "Globalización y complejidad ambiental", (texto basado en el ensayo del mismo autor titulado "Pensar la complejidad Ambiental), en Leff, Enrique, 2000, La Complejidad Ambiental, siglo XXI/ UNAM/PNUMA, México.

Ecología y capital. Racionalidad Ambiental, Democracia participativa y desarrollo sustentable, siglo XXI, México, 2007.

Leida, Azócar, 1995, “Ecoturismo ¿Una alternativa de Desarrollo Sostenible?”, en: Ecoturismo en el Ecuador. 
Trayectorias y Desafíos, UICN, Quito.

López, Alejandro, 2001, "Turismo y desarrollo sostenible". En: Sistema. Vol. 162-163, junio.

Ministerio de Turismo, 2007, Diseño del plan estratégico de desarrollo de turismo sostenible para ecuador PLANDETUR 202, Informe Final.

Muñoz de Escalona, Francisco. El turismo explicado con claridad, 2007, Edición electrónica gratuita, en: www. eumed.net/libros/2007c/310/

OMT. Panorama del turismo internacional. Edición 2008, en: www.untwo.org

Panorama mundial y actualidad del turismo. Edición 2006. Tendencias de los mercados turísticos, España, 2008, en: www.untwo.org

Datos esenciales del turismo., Edición 2007, en: www.untwo.org

Barómetro OMT del turismo mundial, Vol. 5, №3, octubre 2007, en: www.untwo.org

Noticias OMT. Revista de la Organización Mundial del Turismo, año XXI, número 3, 2007, en: www.untwo.org

Pallares, Amalia, 1999, "Construcciones raciales, reforma agraria y movilización indígena en los años 70" en Cervonne, E. y F. Rivera (eds.) Ecuador racista. Imágenes e Identidades, FLACSO, Quito, FLACSO.

Pereiro, Xerardo et al., 2007, Los impactos del turismo en Kuna Yala (Panamá): Turismo y cultura entre los Kuna de Panamá, Editorial Ramón Areces.

PNUMA/PNUD PROGRAMA DE APOYO AL PLANEAMIENTO EN BIODIVERSIDAD, 2001, Guía de Mejores Prácticas para una Integración Sectorial. Integrando la biodiversity en el sector turismo, en:http:// www.unep.org/bpsp/pdfs/tourism_spanish.pdf

PPD, 2005, "Manejo del humedal Ábras de Mantequilla, Fundación para el Desarrollo Agrícola y Rural (FUNDAR)", Informe final de seguimiento y monitoreo-Fundación Ambiente y Sociedad, en: PNUD, Semillas que germina: experiencias comunitarias en la Costa, Centro de investigación, promoción y educación popular, Fundación Ambiente y Sociedad, Quito.

2002, Soluciones Locales a Problemas ambientales globales, Boletín Nº, Quito.

Rist, Gilbert, 2002, Historia de una creencia occidental, Catarata, España.

Sancho, Amparo, 1998, Introducción al turismo, OMT, Madrid.

WWF. "Directrices para el desarrollo del turismo comunitario", julio 2001, en: http://assets.panda.org/downloads/ directrices_para_el_ecoturismo_comunitario_wwf_1.pdf 